\title{
Transfer functions of solar heating systems with pipes for dynamic analysis and control design
}

\author{
Richárd Kicsiny \\ Department of Mathematics, Institute of Environmental Systems, Szent István University, \\ Páter K. u. 1., 2100 Gödöllő, Hungary \\ E-mail address: Kicsiny.Richard@gek.szie.hu \\ Tel.: $+3628522000 / 1413$, fax: +3628410804
}

\begin{abstract}
In view of system efficiency and environmental protection, it is important to harvest solar energy better e.g. by improving solar heating systems. A theoretically founded tool for it is mathematical modelling with the use of system transfer functions. Knowing the transfer functions, the outlet temperature of the system can be determined as a function of the system inputs (solar irradiance, inlet and environment temperatures), the dynamic analysis of the system can be carried out, furthermore, stable feedback control can be designed effectively based on the mathematical methods of control engineering. The designed control can be used e.g. to provide just the minimal required outlet temperature for the consumer and, therefore, to maximize the produced heat with minimal or without any auxiliary heating cost.

Although, pipes can affect the operation of solar heating systems considerably, this effect has not been built in the transfer functions of such systems worked out already in the literature. In this study, new transfer functions for solar heating systems with pipes are proposed based on a validated mathematical model. Transfer function based control design is also given generally. As particular applications, the dynamic analysis and the design of a stable $\mathrm{P}$ control are presented on a real solar heating system. It is also presented quantitatively that the designed $\mathrm{P}$ control is faster and more precise than the most conventional on/off control. Furthermore, the presented methods can be easily adapted for any solar heating system with long pipes equipped with an external heat exchanger.
\end{abstract}

Keywords: Solar heating systems; Pipes; Transfer functions; Control design

Nomenclature

$t$ : time (s),

$\mathcal{L}^{-1}$ : symbol for inverse Laplace transformation

Time-dependent variables

$I_{c}$ : solar irradiance (global) on the collector surface $\left(\mathrm{W} / \mathrm{m}^{2}\right)$,

$T_{c}$ : collector (fluid) temperature $\left({ }^{\circ} \mathrm{C}\right)$,

$T_{p c 1}$ : pipe temperature between the collector outlet and the heat exchanger $\left({ }^{\circ} \mathrm{C}\right)$,

$T_{p c 2}$ : pipe temperature between the heat exchanger and the collector inlet $\left({ }^{\circ} \mathrm{C}\right)$,

$T_{p i 1}$ : pipe temperature before the heat exchanger in the inlet loop $\left({ }^{\circ} \mathrm{C}\right)$,

$T_{p i 2}$ : pipe temperature after the heat exchanger in the inlet loop $\left({ }^{\circ} \mathrm{C}\right)$,

$T_{\text {out }}$ : outlet temperature of the heat exchanger in the inlet loop $\left({ }^{\circ} \mathrm{C}\right)$,

$T_{\text {out }, r}$ : reference (outlet) temperature of the heat exchanger in the inlet loop $\left({ }^{\circ} \mathrm{C}\right)$,

$T_{c e}$ : temperature of the collector environment $\left({ }^{\circ} \mathrm{C}\right)$,

$T_{p c e}$ : environment temperature of the pipes in the collector loop $\left({ }^{\circ} \mathrm{C}\right)$, 
$T_{p i e}$ : environment temperature of the pipes in the inlet loop $\left({ }^{\circ} \mathrm{C}\right)$,

$T_{i}$ : temperature of the inlet (fluid) to the system $\left({ }^{\circ} \mathrm{C}\right)$

$v_{c}$ : flow rate in the collector loop $\left(\mathrm{m}^{3} / \mathrm{s}\right)$,

$v_{i}$ : flow rate in the inlet loop $\left(\mathrm{m}^{3} / \mathrm{s}\right)$

$A_{P}$ : control (tuning) parameter for the proportional control (-),

$c_{c}$ : specific heat capacity of the fluid in the collector $(\mathrm{J} /(\mathrm{kgK}))$,

$c_{i}$ : specific heat capacity of the fluid in the inlet loop $(\mathrm{J} /(\mathrm{kgK}))$,

$k_{p c}$ : heat loss coefficient of the collector pipes to the environment $(\mathrm{W} /(\mathrm{mK})$,

$k_{p i}$ : heat loss coefficient of the storage pipes to the environment $(\mathrm{W} /(\mathrm{mK})$,

$L_{p c}$ : length of the collector pipe in one direction (m),

$L_{p i}:$ length of the storage pipe in one direction $(\mathrm{m})$,

$T_{I}$ : control (tuning) parameter for the integral control (-),

$U_{L e}$ : (overall) heat loss coefficient of the collector $\left(\mathrm{W} /\left(\mathrm{m}^{2} \mathrm{~K}\right)\right)$,

$V_{c}$ : volume of the collector $\left(\mathrm{m}^{3}\right)$,

$V_{p c}$ : volume of the collector pipe in one direction $\left(\mathrm{m}^{3}\right)$,

$V_{p i}$ : volume of the storage pipe in one direction $\left(\mathrm{m}^{3}\right)$,

$\eta_{0}$ : optical efficiency of the collector (-),

$\Phi$ : effectiveness of the heat exchanger (-),

$\rho_{c}$ : mass density of the fluid in the collector $\left(\mathrm{kg} / \mathrm{m}^{3}\right)$,

$\rho_{i}$ : mass density of the fluid in the inlet loop $\left(\mathrm{kg} / \mathrm{m}^{3}\right)$

\section{Introduction}

In view of system efficiency and environmental protection, it is important to harvest solar energy better e.g. by developing solar heating systems (see e.g. (Bíró-Szigeti, 2014)). The theoretically founded tool for it is mathematical modelling.

Various ordinary differential equation (ODE) models are used in the field. In (Buzás and Farkas, 2000), systems with collector, heat exchanger and storage are modelled with a (multidimensional) ODE, which is linear as well as its improved version in (Kicsiny et al., 2014), where system pipes are also modelled with ODEs. The latter linear model, which is used with slight modification in the present paper, is validated and accurate enough for general engineering purposes on modelling and developing solar heating systems. The simple usability is a great advantage of linear models. Furthermore, the nonlinear version of the linear model of (Kicsiny et al., 2014) (proposed there as well) is not much more accurate but much more complicated to apply.

From the mathematical model of Buzás et al. (1998), transfer functions for collectors (Buzás and Kicsiny, 2014) and for simplified solar heating systems without pipe effects (Kicsiny, 2015) have been worked out and used for dynamic analysis. These research results are extended in the present paper by the determination of transfer functions for solar heating systems with pipes and the application of the transfer functions in the dynamic analysis of a particular real system. It can be stated generally that the transfer function based modelling is a relatively new and not frequent approach in the analysis of solar heating systems, especially, 
in the domestic case. Further examples in this subject are the following: Bettayeb et al. (2011) and Huang and Wang (1994) used two-node models to propose collector transfer functions. Several control strategies with pump flow rate modulation have been applied in solar heating systems: in (Löf, 1993), differential, P (proportional), I (integral), PID (proportional integral differential), adaptive and certain kinds of optimal controls are discussed. Generally, the useful heat gain is to be maximized, in some sense, with optimal controls, by flow rate modulation. The Pontryagin maximum principle (Pontryagin, 1962) is used to work out such controls in the field of solar heating systems in (Badescu, 2008; Kovarik and Lesse, 1976; Orbach et al., 1981; Winn and Hull, 1979). For the application of the controls of (Badescu, 2008; Kovarik and Lesse, 1976; Orbach et al., 1981), the knowledge of future meteorological data is needed. This is also the case in (Ntsaluba et al., 2016), where the objective is to maximize the overall gained solar energy of the system while minimize the losses but still meet the heat requirements of the consumer. Clearly, such controls cannot be put directly into practice because the weather is not known in advance. The problem is partially but not fully resolved if it is assumed a priori that only one on and off switches will occur during the considered time interval. In this case a feedback control stands for the optimal one, which, theoretically, can be used in the practice (Orbach et al., 1981), but, the mentioned assumption seems rather speculative.

So-called (often nonlinear) model based controls also exist but they are generally complicated to apply because of the need to predict system output at future time instants and (similarly to the optimal controls) the use of objective functions (Camacho et al., 2007a).

P and PI (proportional integral) controls for collectors (Buzás and Kicsiny, 2014) and for simplified solar heating systems without pipes (Kicsiny, 2015) have been proposed recently. The present work extends these results by means of control design for solar heating systems considering pipe effects according to a future research task set in the Conclusion of (Kicsiny, 2015). Based on studying the literature, not many developments have been carried out on controls (particularly, on transfer function based controls) for domestic type solar heating systems in the recent few decades. Controls based on transfer functions occur in industrial processes, e.g. for solar power plants (Camacho et al., 2007b) and solar desalination plants (Ayala et al., 2011; Fontalvo et al., 2014). The general purpose in such control schemes, as in the present work as well, is that the output temperature follows some reference signal in time by means of the flow rate modulation.

Although, pipes can affect the operation of solar heating systems considerably (Kicsiny et al., 2014; Ntsaluba et al., 2016), this important effect has not been built in the transfer functions of such systems worked out already in the literature. The significant delaying and heat loss effects of pipes in hydraulic systems are studied and modelled generally in (Kicsiny, 2017). The contributions of the present paper are the following in details: by means of the mathematical methods of control engineering, new transfer functions for solar heating systems with pipes are proposed and used for dynamic analysis and control design. According to a there appointed future research task, the present study extends the research results of (Buzás and Kicsiny, 2014 and Kicsiny, 2015), where transfer functions, dynamic analysis and corresponding control have been proposed for solar collectors and simplified solar heating systems (without considering pipe effects). The here worked out transfer functions are based on the slightly modified version of the linear ODE model proposed and validated in (Kicsiny et al., 2014). The main novelty and advantage of this model, in contrast to former ones used to work out transfer functions, is that it takes into account the effects of the pipes in the system, so the worked out transfer functions, as their novelty and advantage as well, also consider pipe effects. This modified model is detailed and validated in the present paper based on measured data. Both the dynamic analysis and the control design are interpreted with respect to a real solar heating system, where the pipe effects are significant and important to model, 
see (Kicsiny et al., 2014; Kicsiny, 2017). Stability criterion is also given for the designed closed-loop proportional $(\mathrm{P})$ control. The efficiency of the proposed control design is shown by means of simulations. The advantages of the transfer functions are considerable: by knowing them, dynamic analysis can be made and feedback control can be designed based on the standard methods of control engineering. Such a control is generally much simpler than optimal and (nonlinear) model based controls but it can follow the reference signal more precisely and rapidly than the on/off control working with constant flow rate (Duffie and Beckman, 2006), which can be called the most conventional control method, even, it is not out of date and still worth researching (Araújo and Pereira, 2017). The simple usability may be the main advantage of the linear approach in connection with the transfer functions.

The organization of the paper is the following: in Section 2, the model for solar heating systems with pipes is presented and validated, for which the transfer functions are worked out in Section 3 and used for the dynamic analysis of a real system. In Section 4, a stable feedback control is designed based on the transfer functions, applied for the mentioned real system and evaluated. Section 5 gives conclusions and proposals for future research.

Because of limits in volume, see e.g. (Bakshi and Bakshi, 2007) for the concepts of control engineering (transfer function, step response, Laplace transformation, P, PI controls, stability, static error, etc.) underlying the present work. Maple (Maplesoft, 2003) and Matlab (Etter et al., 2004) was used for the mathematical calculations required below.

\section{Mathematical model and validation}

This section recalls the basic mathematical model for solar heating systems with pipe effects based on (Kicsiny et al., 2014). The transfer functions will be established according to this model. The studied solar heating system can be seen in Fig. 1.

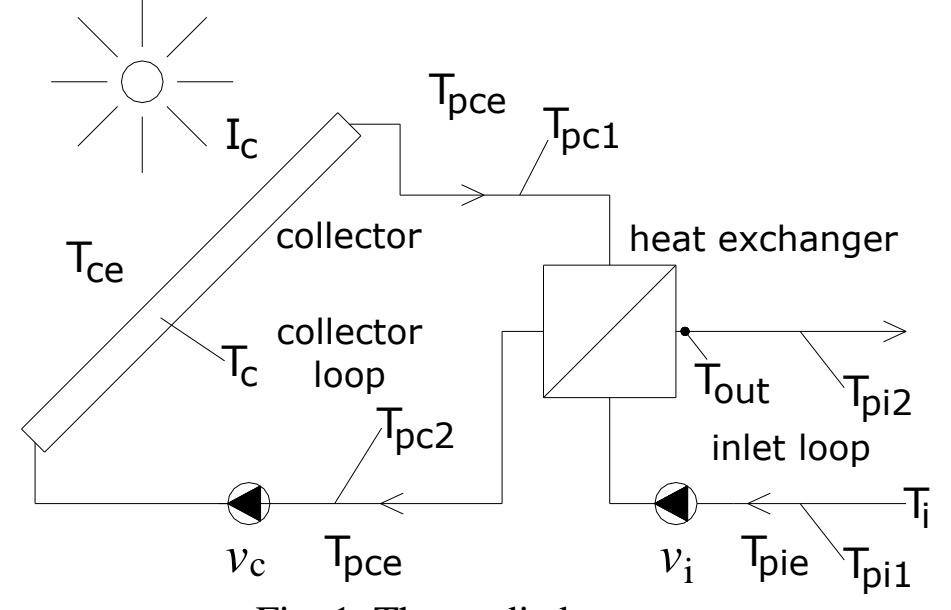

\subsection{Mathematical model}

Fig. 1. The studied system

In fact, a slightly modified version of the linear model of (Kicsiny et al., 2014) is used in the present work as the effect of the pipe between the heat exchanger and the solar storage is omitted now. This is because of that the (homogeneous) temperature of the mentioned pipe $T_{p i 2}$ (see Fig. 1) cannot be conveniently controlled (later in Section 4) by means of the manipulated flow rate $v_{i}$ (see Fig. 9), since this temperature is not increasing in case of any (high) solar irradiance (and permanently switched on collector pump) if the inlet pump (in the inlet loop) is off. This problem does not hold if the controlled variable is the temperature just after the outlet of the heat exchanger at the inlet loop $\left(T_{\text {out }}\right)$. The corresponding mathematical model is formed by Eqs. (1a-e). 
$\frac{d T_{c}(t)}{d t}=\frac{A_{c} \eta_{0}}{\rho_{c} c_{c} V_{c}} I_{c}(t)+\frac{U_{L e} A_{c}}{\rho_{c} c_{c} V_{c}}\left(T_{c e}(t)-T_{c}(t)\right)+\frac{v_{c}}{V_{c}}\left(T_{p c 2}(t)-T_{c}(t)\right)$,

$\frac{d T_{p c 1}(t)}{d t}=\frac{v_{c}}{V_{p c}}\left(T_{c}(t)-T_{p c 1}(t)\right)+\frac{L_{p c} k_{p c}}{\rho_{c} c_{c} V_{p c}}\left(T_{p c e}(t)-T_{p c 1}(t)\right)$,

$\frac{d T_{p c 2}(t)}{d t}=\frac{v_{c}}{V_{p c}}\left(T_{p c 1}(t)-T_{p c 2}(t)\right)+\frac{\Phi \rho_{i} c_{i} v_{i}}{\rho_{c} c_{c} V_{p c}}\left(T_{p i 1}(t)-T_{p c 1}(t)\right)+\frac{L_{p c} k_{p c}}{\rho_{c} c_{c} V_{p c}}\left(T_{p c e}(t)-T_{p c 2}(t)\right)$,

$$
\frac{d T_{p i 1}(t)}{d t}=\frac{v_{i}}{V_{p i}}\left(T_{i}(t)-T_{p i 1}(t)\right)+\frac{L_{p i} k_{p i}}{\rho_{i} c_{i} V_{p i}}\left(T_{p i e}(t)-T_{p i 1}(t)\right),
$$

$T_{\text {out }}(t)=\Phi\left(T_{p c 1}(t)-T_{p i l}(t)\right)+T_{p i l}(t)$

\subsection{Experimental setup}

A particular real solar heating system installed at the campus of the Szent István University (SZIU) Gödöllö, Hungary (Farkas et al., 2000) is used in the present work for validation. Let it be called SZIU system. The installation produces domestic hot water (DHW) for a kindergarten nearby. In our investigation, the solar storage (with $2 \mathrm{~m}^{3}$ ) is not considered. The tap water, from the bottom of the storage, enters into the inlet loop (with temperature $T_{i}$ ), the outlet fluid is the DHW (at temperature $T_{\text {out }}$ ). As the main working components, flat plate solar collectors (collector field) oriented to south with an inclination angle of $45^{\circ}$ (see Fig. 2) and a compact counter flow heat exchanger (see Fig. 3) are used in the system.

185

186

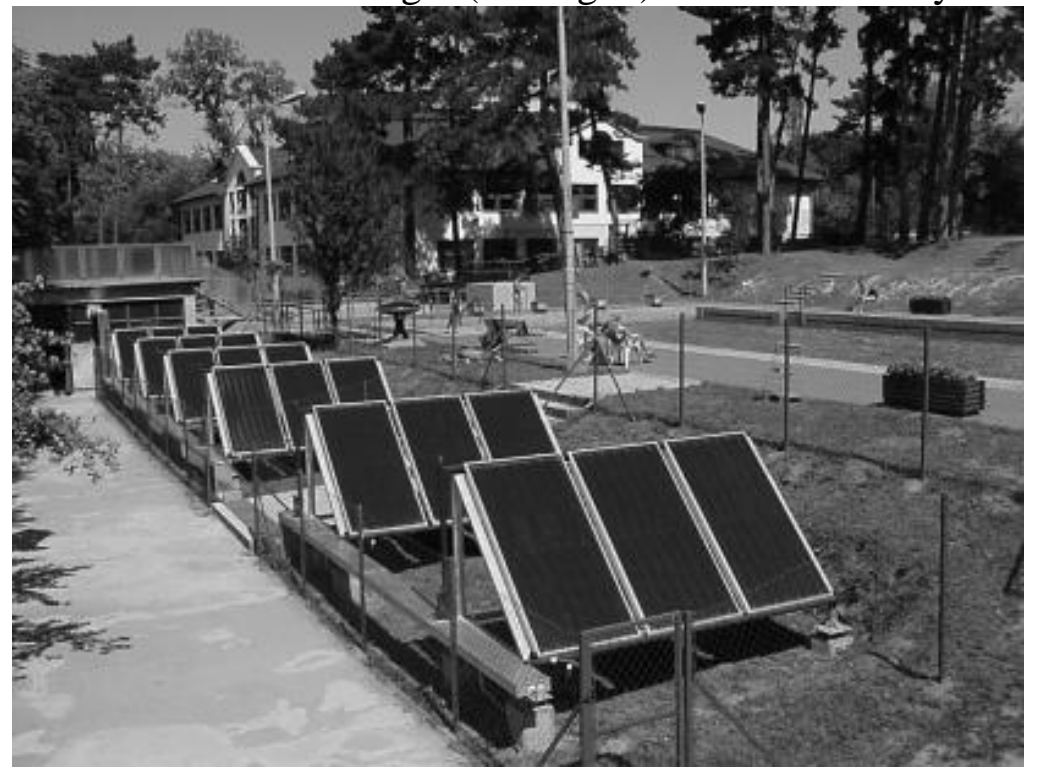

Fig. 2. Solar collector field of the measured system

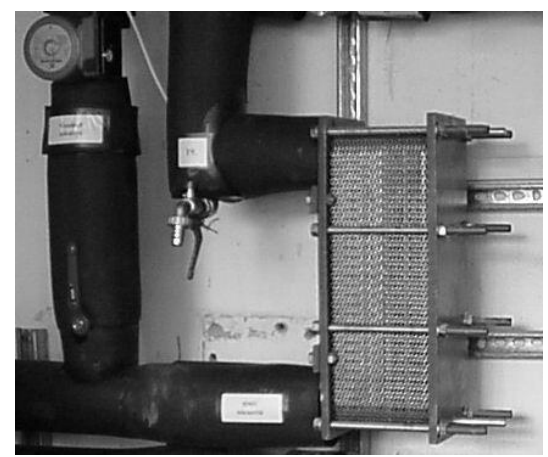


189 The parameter values of the SZIU system are $\eta_{0}=0.74, A_{c}=33.3 \mathrm{~m}^{2}, c_{c}=3623 \mathrm{~J} /(\mathrm{kgK}), \rho_{c}$

$190=1034 \mathrm{~kg} / \mathrm{m}^{3}, V_{c}=0.027 \mathrm{~m}^{3}, c_{i}=4200 \mathrm{~J} /(\mathrm{kgK}), \rho_{i}=1000 \mathrm{~kg} / \mathrm{m}^{3}, U_{L e}=5.2 \mathrm{~W} /\left(\mathrm{m}^{2} \mathrm{~K}\right), k_{p c}=0.45$

$191 \mathrm{~W} /(\mathrm{mK}), k_{p i}=0.25 \mathrm{~W} /(\mathrm{mK}), L_{p c}=80 \mathrm{~m}, L_{p i}=115 \mathrm{~m}, V_{p c}=0.111 \mathrm{~m}^{3}, V_{p i}=0.158 \mathrm{~m}^{3}, \Phi=0.89$,

$192 v_{c}=16.31 / \mathrm{min}\left(0\right.$ or $\left.0.000272 \mathrm{~m}^{3} / \mathrm{s}\right), v_{i}=10.51 / \mathrm{min}\left(0\right.$ or $\left.0.000175 \mathrm{~m}^{3} / \mathrm{s}\right)$ (Kicsiny et al., 193 2014).

194 According to Fig. 1, the values of $T_{i}, T_{c}, T_{c e}=T_{p c e}, T_{p c 1}, T_{p c 2}, T_{p i 1}$ and $T_{\text {out }}$ are measured 195 once a minute (by means of LM 335 type temperature sensors). $I_{c}$ is also measured (by 196 means of a Kipp \& Zonen CM 11 type pyranometer). The pipes of the inlet loop are 197 underground, so $T_{p i e}$ is the soil temperature, which is not measured but estimated because of 198 technical reasons. Nevertheless, it is an acceptable approach, since the soil temperature is 199 nearly constant throughout the year. $v_{c}$ and $v_{i}$ are also measured (by means of Schlumberger 200 FLOSTAR-M 40 type flow meters). ADAM type data acquisition modules collect the 201 measured data and transmit them to a computer for saving and evaluation.

202

203

204

205

206

207

208

209

210

211

\subsection{Validation}

In this section, model (1a-e) is applied for the SZIU system. (For the computer simulations, the model has been realized in (Matlab) Simulink.)

For the validation, the measured values of $T_{i}, I_{c}, T_{c e}=T_{p c e}, v_{c}, v_{i}$ and the estimated value of $T_{p i e}$ are fed into the computer model for (1a-e) along with the measured initial values of $T_{c}$, $T_{p c 1}, T_{p c 2}$, and $T_{p i 1}$. Then the measured and modelled values of the outlet temperature $T_{\text {out }}$ are compared.

Fig. 4 compares the measured and modelled temperatures for a measured day $2^{\text {nd }}$ November 2012, which is a general day with normal operation of the kindergarten and the solar heating system. The operating states (on/off) of the pumps can be also seen in the figure.

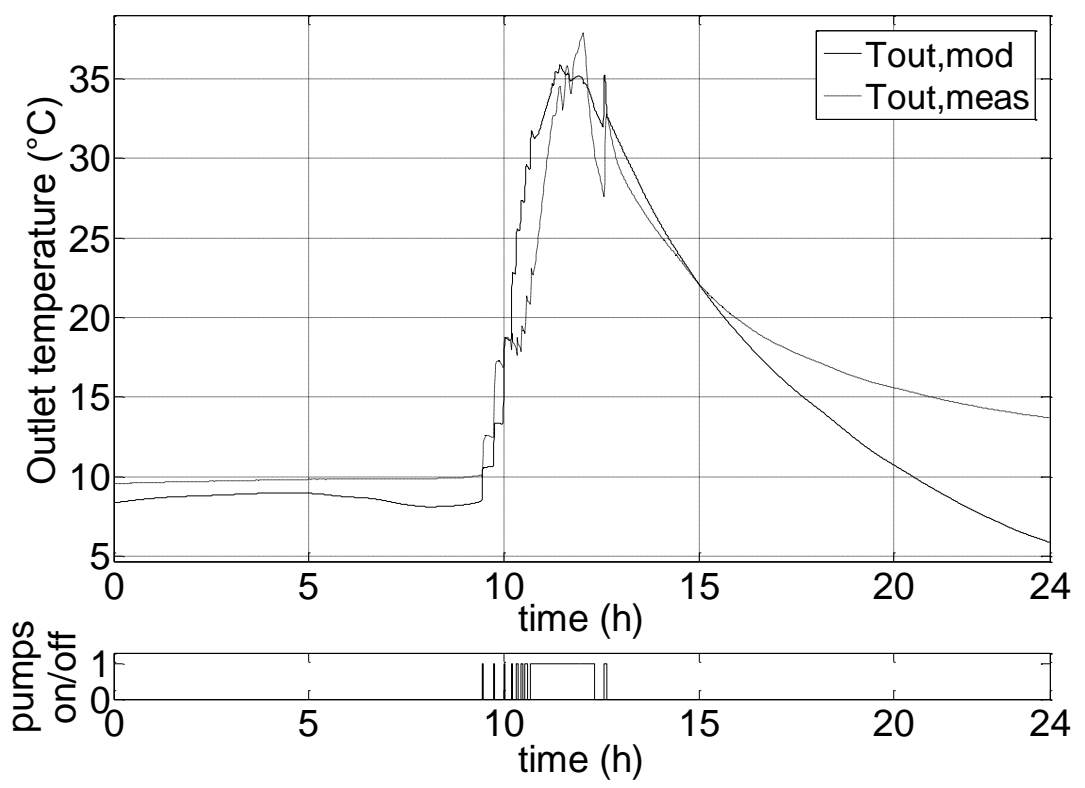

Fig. 4. Modelled and measured outlet temperatures of the solar heating system

The time average of the difference and the absolute difference between the measured and modelled outlet temperatures are $-1.7{ }^{\circ} \mathrm{C}$ and $2.6{ }^{\circ} \mathrm{C}$, respectively. In proportion to the difference between the minimal and maximal measured values of the temperature, the time 
average of the absolute difference (absolute error) is $9.0 \%$, so it can be concluded that the model describes the thermal processes characteristically well with an acceptable precision regarding several engineering aims (developing and studying solar heating systems). Such accuracy is generally acceptable for similar systems in the practice (see e.g. (Kalogirou, 2000)). Thus the mathematical model (1a-e) can be accepted and applied henceforth.

It can be seen in Fig. 4 that the modelling error is higher at the end of the day, when the pumps are permanently off. This may be caused by that the value $\Phi=0.89$ corresponds to switched on pumps and that $T_{\text {out }}$ is measured (technically) on the connecting pipe just after the heat exchanger and not inside the heat exchanger. The temperatures at these places may be quite different if the pumps are off for a considerable time. Nevertheless, this time period is not really important with respect to the performance of the solar heating system, since the system is inactive because of the switched off pumps.

\section{Transfer functions}

\subsection{Derivation of transfer functions}

232 For determining the transfer functions Eqs. (1a-e) is rewritten from time to Laplace domain by means of Laplace transformation according to Eqs. (2a-e).

$s \bar{T}_{c}(s)-T_{c}(0)=\frac{A_{c} \eta_{0}}{\rho_{c} c_{c} V_{c}} \bar{I}_{c}(s)+\frac{U_{L e} A_{c}}{\rho_{c} c_{c} V_{c}}\left(\bar{T}_{c e}(s)-\bar{T}_{c}(s)\right)+\frac{v_{c}}{V_{c}}\left(\bar{T}_{p c 2}(s)-\bar{T}_{c}(s)\right)$,

$s \bar{T}_{p c 1}(s)-T_{p c 1}(0)=\frac{v_{c}}{V_{p c}}\left(\bar{T}_{c}(s)-\bar{T}_{p c 1}(s)\right)+\frac{L_{p c} k_{p c}}{\rho_{c} c_{c} V_{p c}}\left(\bar{T}_{p c e}(s)-\bar{T}_{p c 1}(s)\right)$,

$s \bar{T}_{p c 2}(s)-T_{p c 2}(0)=\frac{v_{c}}{V_{p c}}\left(\bar{T}_{p c 1}(s)-\bar{T}_{p c 2}(s)\right)+\frac{\Phi \rho_{i} c_{i} v_{i}}{\rho_{c} c_{c} V_{p c}}\left(\bar{T}_{p i 1}(s)-\bar{T}_{p c 1}(s)\right)+\frac{L_{p c} k_{p c}}{\rho_{c} c_{c} V_{p c}}\left(\bar{T}_{p c e}(s)-\bar{T}_{p c 2}(s)\right)$,

$s \bar{T}_{p i 1}(s)-T_{p i 1}(0)=\frac{v_{i}}{V_{p i}}\left(\bar{T}_{i}(s)-\bar{T}_{p i 1}(s)\right)+\frac{L_{p i} k_{p i}}{\rho_{i} c_{i} V_{p i}}\left(\bar{T}_{p i e}(s)-\bar{T}_{p i 1}(s)\right)$,

$\bar{T}_{\text {out }}(s)=\Phi\left(\bar{T}_{p c 1}(s)-\bar{T}_{p i 1}(s)\right)+\bar{T}_{p i 1}(s)$,

where overbars denote the variables in Laplace domain, $s$ is the (complex) independent variable in Laplace domain, furthermore, the initial values of $T_{c}, T_{p c 1}, T_{p c 2}$ and $T_{p i 1}$ (state variables) are $T_{c}(0), T_{p c 1}(0), T_{p c 2}(0)$ and $T_{p i 1}(0)$. It is an important advantage of the transformation that the system of linear ODEs (1a-e) is transformed to the simpler linear algebraic form of Eqs. (2a-e). Rearranging Eqs. (2a-e), Eqs. (3a-e) is resulted.

$\bar{T}_{c}(s)=H_{c 0}(s) T_{c}(0)+H_{c 1}(s) \bar{I}_{c}(s)+H_{c 2}(s) \bar{T}_{p c 2}(s)+H_{c 3}(s) \bar{T}_{c e}(s)$,

$$
\bar{T}_{p c 1}(s)=H_{p c 0}(s) T_{p c 1}(0)+H_{p c 11}(s) \bar{T}_{c}(s)+H_{p c e}(s) \bar{T}_{p c e}(s),
$$

$\bar{T}_{p c 2}(s)=H_{p c 0}(s) T_{p c 2}(0)+H_{p c 21}(s) \bar{T}_{p c 1}(s)+H_{p c 22}(s) \bar{T}_{p i 1}(s)+H_{p c e}(s) \bar{T}_{p c e}(s)$,

$\bar{T}_{p i 1}(s)=H_{p i 0}(s) T_{p i 1}(0)+H_{p i 1}(s) \overline{T_{i}}(s)+H_{p i e}(s) \bar{T}_{p i e}(s)$,

$\bar{T}_{\text {out }}(s)=H_{\text {out } 1}(s) \bar{T}_{p c 1}(s)+H_{\text {out } 2}(s) \bar{T}_{p i 1}(s)$, 
where

$H_{c 0}(s)=\frac{\tau_{c}}{\tau_{c} s+1}, \quad H_{c 1}(s)=\frac{\tau_{c}}{\tau_{c} s+1} \cdot \frac{A_{c} \eta_{0}}{\rho_{c} c_{c} V_{c}}, \quad H_{c 2}(s)=\frac{\tau_{c}}{\tau_{c} s+1} \cdot \frac{v_{c}}{V_{c}}, \quad H_{c 3}(s)=\frac{\tau_{c}}{\tau_{c} s+1} \cdot \frac{U_{L e} A_{c}}{\rho_{c} c_{c} V_{c}}$,

$$
H_{p c 0}(s)=\frac{\tau_{p c}}{\tau_{p c} s+1}, \quad H_{p c 11}(s)=\frac{\tau_{p c}}{\tau_{p c} s+1} \cdot \frac{v_{c}}{V_{p c}}, \quad H_{p c e}(s)=\frac{\tau_{p c}}{\tau_{p c} s+1} \cdot \frac{L_{p c} k_{p c}}{\rho_{c} c_{c} V_{p c}},
$$

$$
H_{p c 21}(s)=\frac{\tau_{p c}}{\tau_{p c} s+1} \cdot\left(\frac{v_{c}}{V_{p c}}-\frac{\Phi \rho_{i} c_{i} v_{i}}{\rho_{c} c_{c} V_{p c}}\right), \quad H_{p c 22}(s)=\frac{\tau_{p c}}{\tau_{p c} s+1} \cdot \frac{\Phi \rho_{i} c_{i} v_{i}}{\rho_{c} c_{c} V_{p c}}, \quad H_{p i 0}(s)=\frac{\tau_{p i}}{\tau_{p i} s+1},
$$

$$
H_{p i 11}(s)=\frac{\tau_{p i}}{\tau_{p i} s+1} \cdot \frac{v_{i}}{V_{p i}}, \quad H_{p i e}(s)=\frac{\tau_{p i}}{\tau_{p i} s+1} \cdot \frac{L_{p i} k_{p i}}{\rho_{i} c_{i} V_{p i}}, \quad H_{p i 1}(s)=\frac{\tau_{p i}}{\tau_{p i} s+1} \cdot \frac{v_{i}}{V_{p i}},
$$

$$
H_{p i 21}(s)=\frac{\tau_{p i}}{\tau_{p i} s+1} \cdot \frac{\Phi v_{i}}{V_{p i}}, H_{p i 22}(s)=\frac{\tau_{p i}}{\tau_{p i} s+1} \cdot \frac{(1-\Phi) v_{i}}{V_{p i}}, H_{\text {out } 1}(s)=\Phi, H_{\text {out } 2}(s)=1-\Phi,
$$

where $\tau_{c}, \tau_{p c}, \tau_{p i}$ are the time constants of the collector, the collector pipes (in the collector

loop) and the inlet pipes (in the inlet loop), respectively:

$$
\tau_{c}=\frac{1}{\frac{U_{L e} A_{c}}{\rho_{c} c_{c} V_{c}}+\frac{v_{c}}{V_{c}}}, \tau_{p c}=\frac{1}{\frac{L_{p c} k_{p c}}{\rho_{c} c_{c} V_{p c}}+\frac{v_{c}}{V_{p c}}}, \tau_{p i}=\frac{1}{\frac{L_{p i} k_{p i}}{\rho_{i} c_{i} V_{p i}}+\frac{v_{i}}{V_{p i}}} .
$$

After solving Eqs. (3a-e) for $\bar{T}_{\text {out }}(s)$, Eqs. (4) is resulted.

$$
\begin{aligned}
& \bar{T}_{\text {out }}(s)=H_{i 1}(s) T_{c}(0)+H_{i 2}(s) T_{p c 1}(0)+H_{i 3}(s) T_{p c 2}(0)+H_{i 4}(s) T_{p i 1}(0)+H_{1}(s) \bar{T}_{i}(s)+H_{2}(s) \bar{I}_{c}(s)+H_{3}(s) \bar{T}_{c e}(s)+ \\
& H_{4}(s) \bar{T}_{p c e}(s)+H_{5}(s) \bar{T}_{p i e}(s),
\end{aligned}
$$

262 where

$$
H_{i 1}(s)=\frac{-H_{o u t 1} H_{p c 11} H_{c 0}}{-1+H_{p c 21} H_{p c 11} H_{c 2}}, \quad H_{i 2}(s)=\frac{-H_{o u t 1} H_{p c 0}}{-1+H_{p c 21} H_{p c 11} H_{c 2}}, \quad H_{i 3}(s)=\frac{-H_{o u 1} H_{p c 11} H_{c 2} H_{p c 0}}{-1+H_{p c 21} H_{p c 11} H_{c 2}},
$$

$H_{i 4}(s)=\frac{-H_{p i 0}\left(H_{o u t 1} H_{p c 11} H_{c 2} H_{p c 22}+H_{o u t 2}-H_{o u t 2} H_{p c 21} H_{p c 11} H_{c 2}\right)}{-1+H_{p c 21} H_{p c 11} H_{c 2}}$,

$H_{1}(s)=\frac{-H_{p i 11}\left(H_{o u t 1} H_{p c 11} H_{c 2} H_{p c 22}+H_{o u t 2}-H_{o u t 2} H_{p c 21} H_{p c 11} H_{c 2}\right)}{-1+H_{p c 21} H_{p c 11} H_{c 2}}, \quad H_{2}(s)=\frac{-H_{o u t 1} H_{p c 11} H_{c 1}}{-1+H_{p c 21} H_{p c 11} H_{c 2}}$,

$H_{3}(s)=\frac{-H_{o u t} H_{p c 11} H_{c 3}}{-1+H_{p c 21} H_{p c 11} H_{c 2}}$,

$$
H_{4}(s)=\frac{-H_{o u t} H_{p c e}\left(1+H_{p c 1} H_{c 2}\right)}{-1+H_{p c 21} H_{p c 11} H_{c 2}},
$$

$$
H_{5}(s)=\frac{-H_{p i e}\left(H_{o u t 1} H_{p c 11} H_{c 2} H_{p c 22}+H_{o u t 2}-H_{o u t 2} H_{p c 21} H_{p c 11} H_{c 2}\right)}{-1+H_{p c 21} H_{p c 11} H_{c 2}},
$$

268 where, the independent variable $s$ is not always indicated, for the sake of simplicity.

From the viewpoint of systems engineering, the solar heating system is a system with an output variable ( $T_{\text {out }}$, which is to be controlled in Section 4 ) and input variables (other timedependent but not state variables), when the flow rates are constant, see Fig. 5. 
274 The transfer functions are the quotients of the Laplace transformed form of the output $\bar{T}_{\text {out }}(s)$ and the proper inputs $\bar{T}_{i}(s), \bar{I}_{c}(s), \bar{T}_{c e}(s), \bar{T}_{p c e}(s), \bar{T}_{p i e}(s)$. If the transfer function relating to a selected input is determined, the initial conditions $T_{c}(0), T_{p c 1}(0), T_{p c 2}(0), T_{p i 1}(0)$ and the other inputs are supposed to be zero. According to Eq. (4) the transfer functions for the inputs are $\frac{\bar{T}_{\text {out }}(s)}{\bar{T}_{i}(s)}=H_{1}(s), \frac{\bar{T}_{\text {out }}(s)}{\bar{I}_{c}(s)}=H_{2}(s), \frac{\bar{T}_{\text {out }}(s)}{\bar{T}_{c e}(s)}=H_{3}(s), \frac{\bar{T}_{\text {out }}(s)}{\bar{T}_{p c e}(s)}=H_{4}(s), \frac{\bar{T}_{\text {out }}(s)}{\bar{T}_{\text {pie }}(s)}=H_{5}(s)$.

The response of the outlet temperature regarding the initial conditions can be characterized similarly with functions $\frac{\bar{T}_{\text {out }}(s)}{T_{c}(0)}=H_{i 1}(s), \frac{\bar{T}_{\text {out }}(s)}{T_{p c 1}(0)}=H_{i 2}(s), \frac{\bar{T}_{\text {out }}(s)}{T_{p c 2}(0)}=H_{i 3}(s), \frac{\bar{T}_{\text {out }}(s)}{T_{p i 1}(0)}=H_{i 4}(s)$.

Eq. (4) represents the linear superposition that is the resultant effect of the initial temperatures and inputs is simply the sum of the single effects of the initial temperatures and the inputs.

\subsection{Dynamic analysis}

Dynamic analysis for solar heating systems with pipes can be made with the transfer functions. The unit step responses characterize well the dynamics of a system. The unit step response relating to a selected input is the response (the output) of the system with respect to the input (in time domain), assuming that the input is of unit step type and that the initial values of the state variables and the other inputs are zero. Eq. (5) gives the unit step input generally.

$$
\operatorname{Input}(t)= \begin{cases}0, & t<0, \\ 1, & t \geq 0,\end{cases}
$$

Eq. (6) gives the Laplace transformed form of Input $(t)$.

$$
\overline{\operatorname{Input}}(s)=\frac{1}{s}
$$

Eq. (7) gives the unit step response as output in Laplace domain using $H(s)$, which is the transfer function corresponding to the input.

$$
\overline{\operatorname{Output}}(s)=H(s) \frac{1}{s}
$$

The unit step response can be determined in time domain from $\overline{\operatorname{Output}}(s)$ according to Eq. (8), where $\mathcal{L}^{-1}$ stands for the inverse Laplace transformation.

$$
\operatorname{Output}(t)=\mathcal{L}^{-1}\left[H(s) \frac{1}{s}\right]
$$

According to Eq. (9), the effect of the initial conditions can be also studied in time domain by means of the inverse Laplace transformed form of the product containing the given initial 
condition and its transfer function $H_{i}(s)$ (here, the other initial values and the inputs are assumed to be zero again).

$$
\operatorname{Output}(t)=\mathcal{L}^{-1}\left[H_{i}(s) \cdot \text { Initial condition }\right]=\text { Initial condition } \cdot \mathcal{L}^{-1}\left[H_{i}(s)\right]
$$

Apply the above dynamic analysis on the solar heating system (based on Section 3.1). The unit step responses relating to the inputs $T_{i}, I_{c}, T_{c e}, T_{p c e}$ and $T_{p i e}$ are the following, respectively: $\quad T_{\text {out }}(t)=\mathcal{L}^{-1}\left[H_{1}(s) \frac{1}{s}\right], \quad T_{\text {out }}(t)=\mathcal{L}^{-1}\left[H_{2}(s) \frac{1}{s}\right], \quad T_{\text {out }}(t)=\mathcal{L}^{-1}\left[H_{3}(s) \frac{1}{s}\right]$, $T_{\text {out }}(t)=\mathcal{L}^{-1}\left[H_{4}(s) \frac{1}{s}\right]$ and $T_{\text {out }}(t)=\mathcal{L}^{-1}\left[H_{5}(s) \frac{1}{s}\right]$.

The responses relating to the initial conditions $T_{c}(0), T_{p c 1}(0), T_{p c 2}(0)$ and $T_{p i 1}(0)$ are the following, $\quad$ respectively: $\quad T_{\text {out }}(t)=T_{c}(o) \mathcal{L}^{-1}\left[H_{i 1}(s)\right], \quad T_{\text {out }}(t)=T_{p c 1}(o) \mathcal{L}^{-1}\left[H_{i 2}(s)\right]$, $T_{\text {out }}(t)=T_{p c 2}(o) \mathcal{L}^{-1}\left[H_{i 3}(s)\right]$ and $T_{\text {out }}(t)=T_{p i 1}(o) \mathcal{L}^{-1}\left[H_{i 4}(s)\right]$.

\subsubsection{Dynamic analysis of a real system}

The above analysis for solar heating systems is presented for the SZIU system (in case of switched on pumps). Eq. (10) gives the unit step response of the SZIU system relating to $T_{i}$.

$$
T_{\text {out }}(t)=0.72+0.004 e^{-0.012 t}-0.13 e^{-0.004 t}-27.481 e^{-0.001 t}+26.89 e^{-0.001 t},
$$

where $t$ : time (s). The graph of the function can be seen in Fig. 6 .

\section{Effect of $\mathrm{Ti}$}

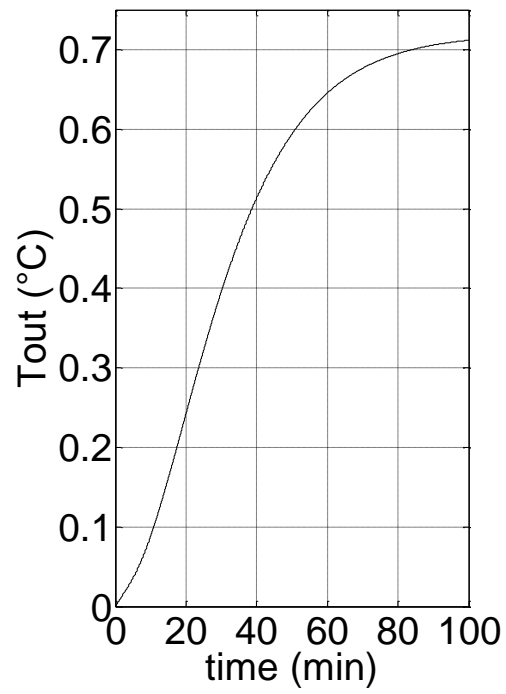

Fig. 6. Response of the system with respect to the unit step of $T_{i}$

Eqs. (11), (12), (13) and (14) give the unit step response relating to $I_{c}, T_{c e}, T_{p c e}$ and $T_{p i e}$.

$$
\begin{gathered}
T_{\text {out }}(t)=0.0249+0.005 e^{-0.0012 t}-0.009 e^{-0.004 t}-0.021 e^{-0.001 t}, \\
T_{\text {out }}(t)=0.175+0.0389 e^{-0.012 t}-0.066 e^{-0.004 t}-0.147 e^{-0.001 t}, \\
T_{\text {out }}(t)=0.078-0.002 e^{-0.012 t}+0.01 e^{-0.004 t}-0.085 e^{-0.001 t}, \\
T_{\text {out }}(t)=0.028+0.0002 e^{-0.012 t}-0.005 e^{-0.004 t}-1.075 e^{-0.001 t}+1.052 e^{-0.001 t}
\end{gathered}
$$


Eq. (15) gives the response relating to $T_{c}(0)\left(T_{c}(0)=1{ }^{\circ} \mathrm{C}\right)$ (see Fig. 7 as well).

$$
T_{\text {out }}(t)=-0.258 e^{-0.012 t}+0.163 e^{-0.004 t}+0.096 e^{-0.001 t}
$$

Effect of $\mathrm{Tc}(0)$
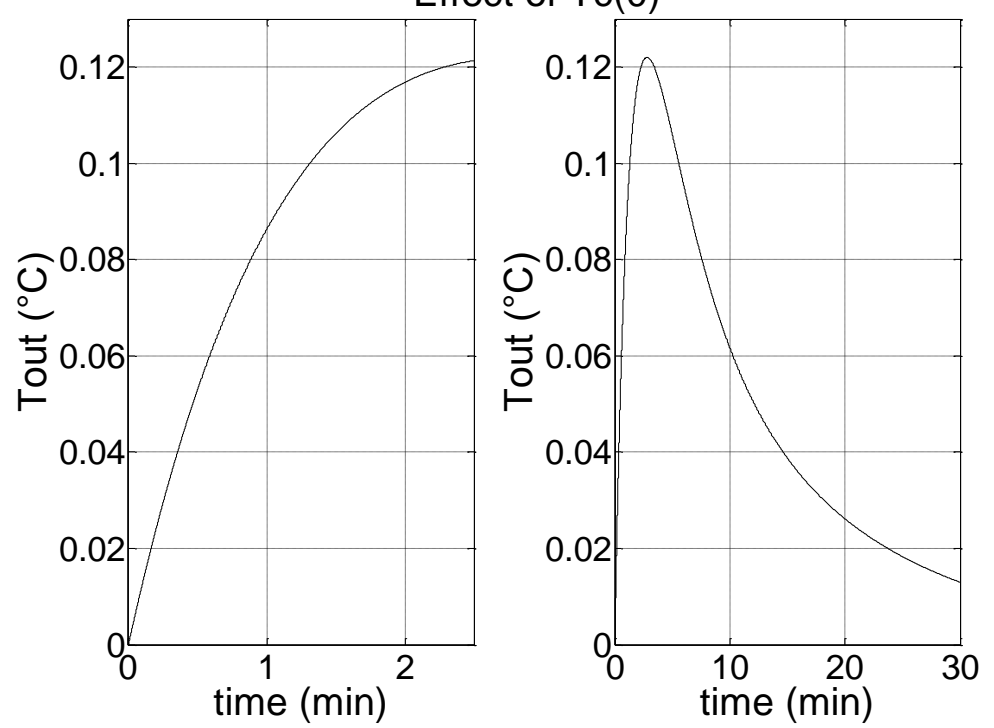

Fig. 7. Response of the system with respect to $T_{c}(0)=1{ }^{\circ} \mathrm{C}$

Eqs. (16), (17) and (18) give the response relating to $T_{p c 1}(0)\left(T_{p c 1}(0)=1{ }^{\circ} \mathrm{C}\right), T_{p c 2}(0)\left(T_{p c 2}(0)=1\right.$ $\left.{ }^{\circ} \mathrm{C}\right)$ and $T_{p i 1}(0)\left(T_{p i 1}(0)=1{ }^{\circ} \mathrm{C}\right)$.

$$
\begin{gathered}
T_{\text {out }}(t)=-0.028 e^{-0.012 t}+0.501 e^{-0.004 t}+0.417 e^{-0.001 t}, \\
T_{\text {out }}(t)=0.3 e^{-0.012 t}-0.967 e^{-0.004 t}+0.677 e^{-0.001 t}, \\
T_{\text {out }}(t)=-0.044 e^{-0.012 t}+0.493 e^{-0.004 t}+27.598 e^{-0.001 t}-27.937 e^{-0.001 t}
\end{gathered}
$$

If all inputs and initial conditions affect simultaneously, the resultant output is a simple sum of functions (10)-(18) based on the superposition principle (see Eq. (19) and Fig. 8).

$$
T_{\text {out }}(t)=0.72+0.004 e^{-0.012 t}-0.129 e^{-0.004 t}-27.481 e^{-0.001 t}+26.886 e^{-0.001 t}
$$

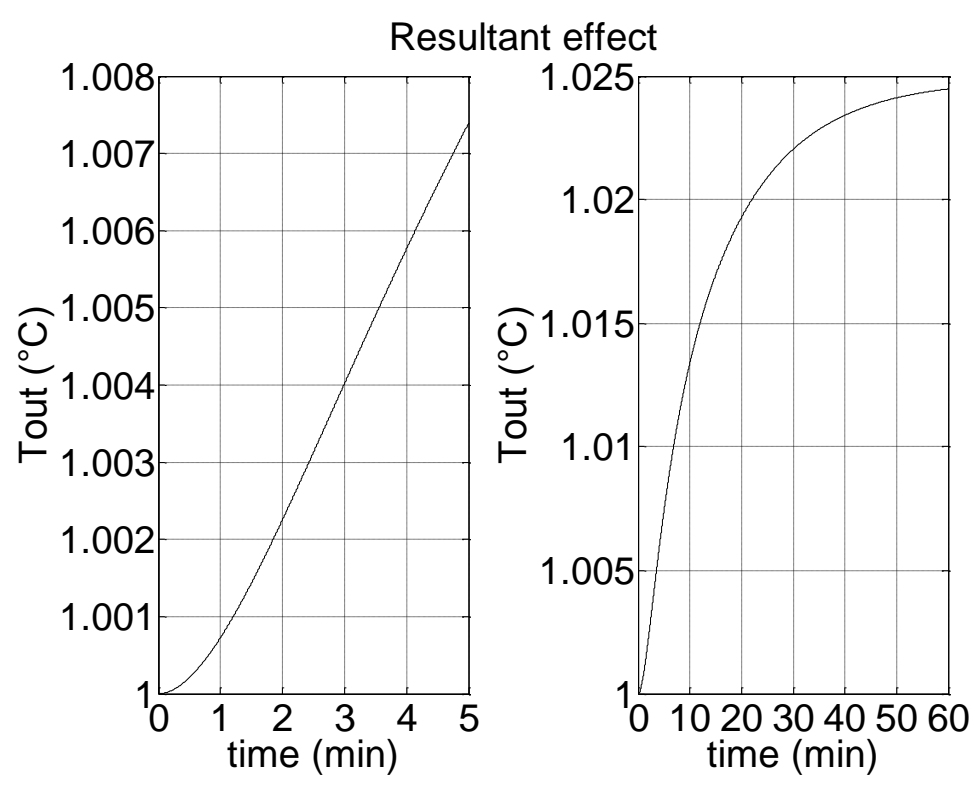


337 For better visibility, the responses in Figs. 6, 7 and 8 are shown for different time periods.

338 Remark 3.1

339 The largest effect of the inputs to the outlet temperature $T_{\text {out }}$ is produced by the unit change of $340 T_{i}$, according to Eqs. (10)-(14), since the function of Eq. (10) has the biggest maximum 341 (bigger than $\left.0.72{ }^{\circ} \mathrm{C}\right) . T_{p c 1}(0)$ has the largest effect regarding the initial conditions.

\section{System control}

343 Stable control can be determined for solar heating systems with pipes by means of the transfer 344 functions and the well-tried tools of control engineering. Here, the outlet temperature is the controlled variable, which is to be changed in time according to a prefixed reference function by proper flow rate modulation in the inlet loop, so $v_{i}$ (as manipulated variable) can be varied now. $v_{c}$ is maximal (constant) to maintain the collector temperature always at a minimal level. In this way, the efficiency of the collector (and the solar heating system) is maximal in case of any $v_{i}$ value. It is assumed that the collector temperature is always high enough to increase $T_{\text {out }}$ even if $v_{c}$ is maximal. (Otherwise, $v_{c}$ could be changed if needed while always kept as high as possible, since it is enough for us to increase $T_{\text {out }}$ to any small extent).

353

354

355

356

357

358

359

360

361

362

363

364

365

366 Functions $T_{i}, I_{c}, T_{c e}, T_{p c e}$ and $T_{p i e}$ are disturbances now. Fig. 9 summarizes the control.

\section{$T_{i} \quad I_{c} \quad T_{c e} T_{p c e} T_{p i e}:$ disturbances}

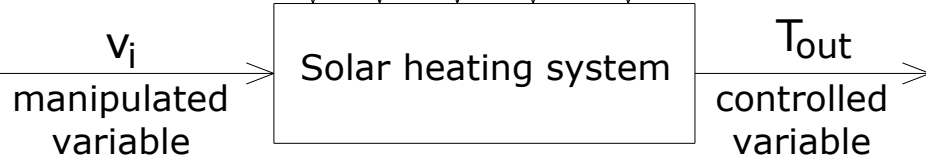

Fig. 9. Scheme of the solar heating system regarding control

Now, not every coefficient is constant in system (1a-e), since neither is $v_{i}(t)$ constant, even system (1a-e) is not linear in $T_{p c 1}(t), T_{p i l}(t), T_{i}(t), v_{i}(t)$, because of the products $v_{i}(t) T_{p c 1}(t)$, $v_{i}(t) T_{p i l}(t), v_{i}(t) T_{i}(t)$ in (1c and d), so the linear methods of control engineering cannot be applied directly. First, Eqs. (1a-e) should be linearized at a convenient operating point.

\subsection{Model linearization}

Such an equilibrium of Eqs. (1a-e) is chosen for operating point, which represents a kind of "average" circumstances, that is, when each of $T_{c}(t), T_{p c 1}(t), T_{p c 2}(t), T_{p i 1}(t), T_{\text {out }}(t), T_{i}(t)$, $I_{c}(t), T_{c e}(t), T_{p c e}(t), T_{p i e}(t)$ is constant and is the approximate mean value between the lower and upper limits of its real occurring values. Let $T_{c}^{0}, T_{p c 1}^{0}, T_{p c 2}^{0}, T_{p i 1}^{0}, T_{o u t}^{0}, T_{i}^{0}, I_{c}^{0}, T_{c e}^{0}, T_{p c e}^{0}$, $T_{p i e}^{0}$ and $v_{i}^{0}$ denote these constants at such operating point. The r.h.s. of (1a-e) are zero at this operating point as it is an equilibrium (see Eqs. (20a-e)).

$0=\frac{A_{c} \eta_{0}}{\rho_{c} c_{c} V_{c}} I_{c}^{0}+\frac{U_{L e} A_{c}}{\rho_{c} c_{c} V_{c}}\left(T_{c e}^{0}-T_{c}^{0}\right)+\frac{v_{c}}{V_{c}}\left(T_{p c 2}^{0}-T_{c}^{0}\right)$ 
$0=\frac{v_{c}}{V_{p c}}\left(T_{c}^{0}-T_{p c 1}^{0}\right)+\frac{L_{p c} k_{p c}}{\rho_{c} c_{c} V_{p c}}\left(T_{p c e}^{0}-T_{p c 1}^{0}\right)$

$0=\frac{v_{c}}{V_{p c}}\left(T_{p c 1}^{0}-T_{p c 2}^{0}\right)+\frac{\Phi \rho_{i} c_{i} v_{i}^{0}}{\rho_{c} c_{c} V_{p c}}\left(T_{p i 1}^{0}-T_{p c 1}^{0}\right)+\frac{L_{p c} k_{p c}}{\rho_{c} c_{c} V_{p c}}\left(T_{p c e}^{0}-T_{p c 2}^{0}\right)$

$0=\frac{v_{i}^{0}}{V_{p i}}\left(T_{i}^{0}-T_{p i 1}^{0}\right)+\frac{L_{p i} k_{p i}}{\rho_{i} c_{i} V_{p i}}\left(T_{p i e}^{0}-T_{p i 1}^{0}\right)$,

$T_{o u t}^{0}=\Phi\left(T_{p c 1}^{0}-T_{p i 1}^{0}\right)+T_{p i 1}^{0}$

371 Eqs. (1c and d) have the form of Eqs. (21c and d).

$$
\begin{gathered}
\frac{d T_{p c 2}(t)}{d t}=F\left(T_{p c 1}(t), T_{p c 2}(t), T_{p i 1}(t), T_{p c e}(t), v_{i}(t)\right), \\
\frac{d T_{p i 1}(t)}{d t}=F\left(T_{p i 1}(t), T_{i}(t), T_{p i e}(t), v_{i}(t)\right)
\end{gathered}
$$

374 Eqs. (22c and d) shows the linearized version of Eqs. (1c and d) at the operating point.

$$
\begin{aligned}
& \frac{d T_{p c 2}(t)}{d t}=F\left(T_{p c 1}^{0}, T_{p c 2}^{0}, T_{p i 1}^{0}, T_{p c e}^{0}, v_{i}^{0}\right)+\frac{\partial F}{\partial T_{p c 1}}\left(T_{p c 1}^{0}, T_{p c 2}^{0}, T_{p i 1}^{0}, T_{p c e}^{0}, v_{i}^{0}\right) \cdot\left(T_{p c 1}(t)-T_{p c 1}^{0}\right)+ \\
& \frac{\partial F}{\partial T_{p c 2}}\left(T_{p c 1}^{0}, T_{p c 2}^{0}, T_{p i 1}^{0}, T_{p c e}^{0}, v_{i}^{0}\right) \cdot\left(T_{p c 2}(t)-T_{p c 2}^{0}\right)+\frac{\partial F}{\partial T_{p i 1}}\left(T_{p c 1}^{0}, T_{p c 2}^{0}, T_{p i 1}^{0}, T_{p c e}^{0}, v_{i}^{0}\right) \cdot\left(T_{p i 1}(t)-T_{p i 1}^{0}\right)+
\end{aligned}
$$

$\frac{\partial F}{\partial T_{p c e}}\left(T_{p c 1}^{0}, T_{p c 2}^{0}, T_{p i 1}^{0}, T_{p c e}^{0}, v_{i}^{0}\right) \cdot\left(T_{p c e}(t)-T_{p c e}^{0}\right)+\frac{\partial F}{\partial v_{i}}\left(T_{p c 1}^{0}, T_{p c 2}^{0}, T_{p i 1}^{0}, T_{p c e}^{0}, v_{i}^{0}\right) \cdot\left(v_{i}(t)-v_{i}^{0}\right)=0+$

$\left(\frac{v_{c}}{V_{p c}}-\frac{\Phi \rho_{i} c_{i} v_{i}^{0}}{\rho_{c} c_{c} V_{p c}}\right) \cdot\left(T_{p c 1}(t)-T_{p c 1}^{0}\right)-\left(\frac{v_{c}}{V_{p c}}-\frac{L_{p c} k_{p c}}{\rho_{c} c_{c} V_{p c}}\right) \cdot\left(T_{p c 2}(t)-T_{p c 2}^{0}\right)+\frac{\Phi \rho_{i} c_{i} v_{i}^{0}}{\rho_{c} c_{c} V_{p c}}\left(T_{p i 1}(t)-T_{p i 1}^{0}\right)+$

$\frac{L_{p c} k_{p c}}{\rho_{c} c_{c} V_{p c}}\left(T_{p c e}(t)-T_{p c e}^{0}\right)+\frac{\Phi \rho_{i} c_{i}\left(T_{p i 1}^{0}-T_{p c 1}^{0}\right)}{\rho_{c} c_{c} V_{p c}}\left(v_{i}(t)-v_{i}^{0}\right)$,

376

$$
\begin{aligned}
& \frac{d T_{p i 1}(t)}{d t}=F\left(T_{p i 1}^{0}, T_{i}^{0}, T_{p i e}^{0}, v_{i}^{0}\right)+\frac{\partial F}{\partial T_{p i 1}}\left(T_{p i 1}^{0}, T_{i}^{0}, T_{p i e}^{0}, v_{i}^{0}\right) \cdot\left(T_{p i 1}(t)-T_{p i 1}^{0}\right)+ \\
& \frac{\partial F}{\partial T_{i}}\left(T_{p i l}^{0}, T_{i}^{0}, T_{p i e}^{0}, v_{i}^{0}\right) \cdot\left(T_{i}(t)-T_{i}^{0}\right)+\frac{\partial F}{\partial T_{p i e}}\left(T_{p i l}^{0}, T_{i}^{0}, T_{p i e}^{0}, v_{i}^{0}\right) \cdot\left(T_{p i e}(t)-T_{p i e}^{0}\right)+
\end{aligned}
$$

$$
\begin{aligned}
& \frac{\partial F}{\partial v_{i}}\left(T_{p i l}^{0}, T_{i}^{0}, T_{p i e}^{0}, v_{i}^{0}\right) \cdot\left(v_{i}(t)-v_{i}^{0}\right)=0-\left(\frac{v_{i}^{0}}{V_{p i}}+\frac{L_{p i} k_{p i}}{\rho_{i} c_{i} V_{p i}}\right) \cdot\left(T_{p i 1}(t)-T_{p i 1}^{0}\right)+\frac{v_{i}^{0}}{V_{p i}} \cdot\left(T_{i}(t)-T_{i}^{0}\right)+ \\
& \frac{L_{p i} k_{p i}}{\rho_{i} c_{i} V_{p i}}\left(T_{p i e}(t)-T_{p i e}^{0}\right)+\frac{T_{i}^{0}-T_{p i 1}^{0}}{V_{p i}}\left(v_{i}(t)-v_{i}^{0}\right)
\end{aligned}
$$

Eqs. (1a,b and e) are linear corresponding to each time-dependent function, so the coefficients

in Eqs. (1a,b and e) remain the same below in the linearized model Eqs. (23 a-e). 
$381 \quad$ Let $\quad \tilde{T}_{c}(t)=T_{c}(t)-T_{c}^{0}, \quad \tilde{T}_{p c 1}(t)=T_{p c 1}(t)-T_{p c 1}^{0}, \quad \tilde{T}_{p c 2}(t)=T_{p c 2}(t)-T_{p c 2}^{0}, \quad \tilde{T}_{p i 1}(t)=T_{p i 1}(t)-T_{p i 1}^{0}$, $382 \tilde{T}_{\text {out }}(t)=T_{\text {out }}(t)-T_{\text {out }}^{0}, \quad \tilde{T}_{i}(t)=T_{i}(t)-T_{i}^{0}, \quad \tilde{I}_{c}(t)=I_{c}(t)-I_{c}^{0}, \quad \tilde{T}_{\text {ce }}(t)=T_{c e}(t)-T_{c e}^{0}$, $383 \tilde{T}_{p c e}(t)=T_{p c e}(t)-T_{p c e}^{0}, \widetilde{T}_{p i e}(t)=T_{p i e}(t)-T_{p i e}^{0}, \widetilde{v}_{i}(t)=v_{i}(t)-v_{i}^{0}$ in the linearized Eqs. (23 a-e).

$384 \quad \frac{d \tilde{T}_{c}(t)}{d t}=\frac{A_{c} \eta_{0}}{\rho_{c} c_{c} V_{c}} \tilde{I}_{c}(t)+\frac{U_{L e} A_{c}}{\rho_{c} c_{c} V_{c}}\left(\tilde{T}_{c e}(t)-\tilde{T}_{c}(t)\right)+\frac{v_{c}}{V_{c}}\left(\tilde{T}_{p c 2}(t)-\tilde{T}_{c}(t)\right)$, 385

$\frac{d \tilde{T}_{p c 1}(t)}{d t}=\frac{v_{c}}{V_{p c}}\left(\widetilde{T}_{c}(t)-\widetilde{T}_{p c 1}(t)\right)+\frac{L_{p c} k_{p c}}{\rho_{c} c_{c} V_{p c}}\left(\widetilde{T}_{p c e}(t)-\widetilde{T}_{p c 1}(t)\right)$,

$\frac{d \tilde{T}_{p c 2}(t)}{d t}=\frac{v_{c}}{V_{p c}}\left(\widetilde{T}_{p c 1}(t)-\widetilde{T}_{p c 2}(t)\right)+\frac{\Phi \rho_{i} c_{i} v_{i}^{0}}{\rho_{c} c_{c} V_{p c}}\left(\widetilde{T}_{p i 1}(t)-\widetilde{T}_{p c 1}(t)\right)+\frac{L_{p c} k_{p c}}{\rho_{c} c_{c} V_{p c}}\left(\widetilde{T}_{p c e}(t)-\widetilde{T}_{p c 2}(t)\right)+$

386 $\frac{\Phi \rho_{i} c_{i}\left(T_{p i 1}^{0}-T_{p c 1}^{0}\right)}{\rho_{c} c_{c} V_{p c}} \widetilde{v}_{i}(t)$,

$\frac{d \widetilde{T}_{p i 1}(t)}{d t}=\frac{v_{i}^{0}}{V_{p i}}\left(\widetilde{T}_{i}(t)-\widetilde{T}_{p i l}(t)\right)+\frac{L_{p i} k_{p i}}{\rho_{i} c_{i} V_{p i}}\left(\widetilde{T}_{p i e}(t)-\widetilde{T}_{p i 1}(t)\right)+\frac{T_{i}^{0}-T_{p i l}^{0}}{V_{p i}} \widetilde{v}_{i}(t)$,

388

$\tilde{T}_{\text {out }}(t)=\Phi\left(\tilde{T}_{p c 1}(t)-\tilde{T}_{p i 1}(t)\right)+\tilde{T}_{p i 1}(t)$

389 Rewrite Eqs. (23a-e) into Laplace domain with $\widetilde{T}_{c}(0)=\widetilde{T}_{p c 1}(0)=\widetilde{T}_{p c 2}(0)=\widetilde{T}_{p i l}(0)=0{ }^{\circ} \mathrm{C}$ :

390

$s \overline{\tilde{T}_{c}}(s)=\frac{A_{c} \eta_{0}}{\rho_{c} c_{c} V_{c}} \overline{\tilde{I}}_{c}(s)+\frac{U_{L e} A_{c}}{\rho_{c} c_{c} V_{c}}\left(\overline{\widetilde{T}}_{c e}(s)-\overline{\widetilde{T}}_{c}(s)\right)+\frac{v_{c}}{V_{c}}\left(\overline{\widetilde{T}}_{p c 2}(s)-\overline{\tilde{T}}_{c}(s)\right)$,

391

$s \overline{\widetilde{T}}_{p c 1}(s)=\frac{v_{c}}{V_{p c}}\left(\overline{\widetilde{T}}_{c}(s)-\overline{\widetilde{T}}_{p c 1}(s)\right)+\frac{L_{p c} k_{p c}}{\rho_{c} c_{c} V_{p c}}\left(\overline{\widetilde{T}}_{p c e}(s)-\overline{\widetilde{T}}_{p c 1}(s)\right)$,

392

$s \overline{\widetilde{T}}_{p c 2}(s)=\frac{v_{c}}{V_{p c}}\left(\overline{\widetilde{T}}_{p c 1}(s)-\overline{\widetilde{T}}_{p c 2}(s)\right)+\frac{\Phi \rho_{i} c_{i} v_{i}^{0}}{\rho_{c} c V_{p c}}\left(\overline{\widetilde{T}}_{p i 1}(s)-\overline{\widetilde{T}}_{p c 1}(s)\right)+\frac{L_{p c} k_{p c}}{\rho_{c} c V_{c} V_{p c}}\left(\overline{\widetilde{T}}_{p c e}(s)-\overline{\widetilde{T}}_{p c 2}(s)\right)+$

$\frac{\Phi \rho_{i} c_{i}\left(T_{p i 1}^{0}-T_{p c 1}^{0}\right)}{\rho_{c} c_{c} V_{p c}} \bar{v}_{i}(s)$,

393

$s \overline{\widetilde{T}}_{p i l}(s)=\frac{v_{i}^{0}}{V_{p i}}\left(\overline{\widetilde{T}}_{i}(s)-\overline{\widetilde{T}}_{p i l}(s)\right)+\frac{L_{p i} k_{p i}}{\rho_{i} c_{i} V_{p i}}\left(\overline{\widetilde{T}}_{p i e}(s)-\overline{\widetilde{T}}_{p i l}(s)\right)+\frac{T_{i}^{0}-T_{p i 1}^{0}}{V_{p i}} \overline{\widetilde{v}}_{i}(s)$,

$394 \quad \overline{\widetilde{T}}_{\text {out }}(s)=\Phi\left(\overline{\widetilde{T}}_{p c 1}(s)-\overline{\widetilde{T}}_{p i l}(s)\right)+\overline{\widetilde{T}}_{p i 1}(s)$.

395 Based on the linear superposition principle, the sum of the separate effects of the inputs is the 396 resultant effect according to Eq. (25).

$\overline{\widetilde{T}}_{\text {out }}(s)=\tilde{H}_{1}(s) \overline{\widetilde{T}}_{i}(s)+\tilde{H}_{2}(s) \overline{\tilde{I}}_{c}(s)+\tilde{H}_{3}(s) \overline{\widetilde{T}}_{c e}(s)+\tilde{H}_{4}(s) \overline{\widetilde{T}}_{p c e}(s)+\tilde{H}_{5}(s) \overline{\widetilde{T}}_{p i e}(s)+\tilde{H}_{6}(s) \overline{\widetilde{v}}_{i}(s)$,

where 
$\tilde{H}_{1}(s)=\frac{-\tilde{H}_{p i 11}\left(\tilde{H}_{o u t 1} \tilde{H}_{p c 11} \tilde{H}_{c 2} \tilde{H}_{p c 22}+\tilde{H}_{o u t 2}-\tilde{H}_{o u t 2} \tilde{H}_{p c 21} \tilde{H}_{p c 11} \tilde{H}_{c 2}\right)}{-1+\tilde{H}_{p c 21} \tilde{H}_{p c 11} \tilde{H}_{c 2}}, \quad \tilde{H}_{2}(s)=\frac{-\tilde{H}_{o u t 1} \tilde{H}_{p c 11} \tilde{H}_{c 1}}{-1+\tilde{H}_{p c 21} \tilde{H}_{p c 11} \tilde{H}_{c 2}}$,

400

$\tilde{H}_{3}(s)=\frac{-\tilde{H}_{o u t 1} \tilde{H}_{p c 11} \tilde{H}_{c 3}}{-1+\tilde{H}_{p c 21} \tilde{H}_{p c 11} \tilde{H}_{c 2}}$

$\tilde{H}_{4}(s)=\frac{-\tilde{H}_{o u t 1} \tilde{H}_{p c e}\left(1+\tilde{H}_{p c 11} \tilde{H}_{c 2}\right)}{-1+\tilde{H}_{p c 21} \tilde{H}_{p c 11} \tilde{H}_{c 2}}$,

401

$\tilde{H}_{5}(s)=\frac{-\tilde{H}_{p i e}\left(\tilde{H}_{o u t 1} \tilde{H}_{p c 11} \tilde{H}_{c 2} \tilde{H}_{p c 22}+\tilde{H}_{o u t 2}-\tilde{H}_{o u t 2} \tilde{H}_{p c 21} \tilde{H}_{p c 11} \tilde{H}_{c 2}\right)}{-1+\tilde{H}_{p c 21} \tilde{H}_{p c 11} \tilde{H}_{c 2}}$,

402

$\tilde{H}_{6}(s)=\frac{-\tilde{H}_{o u t 2} \tilde{H}_{p i 12} \tilde{H}_{p c 21} \tilde{H}_{p c 11} \tilde{H}_{c 2}+\tilde{H}_{o u t 1} \tilde{H}_{p c 11} \tilde{H}_{c 2} \tilde{H}_{p c 22} \tilde{H}_{p i 12}+\tilde{H}_{o u t 1} \tilde{H}_{p c 11} \tilde{H}_{c 2} \tilde{H}_{p c 23}+\tilde{H}_{o u t 2} \tilde{H}_{p i 12}}{-1+\tilde{H}_{p c 21} \tilde{H}_{p c 11} \tilde{H}_{c 2}}$,

403 where

404

$\tilde{H}_{c 1}(s)=H_{c 1}(s), \quad \tilde{H}_{c 2}(s)=H_{c 2}(s), \quad \tilde{H}_{c 3}(s)=H_{c 3}(s), \quad \tilde{H}_{p c 11}(s)=H_{p c 11}(s), \quad \tilde{H}_{p c e}(s)=H_{p c e}(s)$,

405

$\tilde{H}_{p c 21}(s)=\frac{\tau_{p c}}{\tau_{p c} s+1} \cdot\left(\frac{v_{c}}{V_{p c}}-\frac{\Phi \rho_{i} c_{i} v_{i}^{0}}{\rho_{c} c_{c} V_{p c}}\right)$,

$\tilde{H}_{p c 22}(s)=\frac{\tau_{p c}}{\tau_{p c} s+1} \cdot \frac{\Phi \rho_{i} c_{i} v_{i}^{0}}{\rho_{c} c_{c} V_{p c}}$,

406

$\tilde{H}_{p c 23}(s)=\frac{\tau_{p c}}{\tau_{p c} s+1} \cdot \frac{\Phi \rho_{i} c_{i}\left(T_{p i 1}^{0}-T_{p c 1}^{0}\right)}{\rho_{c} c_{c} V_{p c}}, \quad \tilde{H}_{p i 11}(s)=\frac{\tilde{\tau}_{p i}}{\tilde{\tau}_{p i} s+1} \cdot \frac{v_{i}^{0}}{V_{p i}}, \quad \tilde{H}_{p i 12}(s)=\frac{\tilde{\tau}_{p i}}{\tilde{\tau}_{p i} s+1} \cdot \frac{T_{i}^{0}-T_{p i 1}^{0}}{V_{p i}}$,

407

$\tilde{H}_{p i e}(s)=\frac{\tilde{\tau}_{p i}}{\tilde{\tau}_{p i} s+1} \cdot \frac{L_{p i} k_{p i}}{\rho_{i} c_{i} V_{p i}}, \quad \tilde{H}_{p i 21}(s)=\frac{\tilde{\tau}_{p i}}{\tilde{\tau}_{p i} s+1} \cdot \frac{\Phi v_{i}^{0}}{V_{p i}}$,

$\tilde{H}_{p i 22}(s)=\frac{\tilde{\tau}_{p i}}{\tilde{\tau}_{p i} s+1} \cdot \frac{(1-\Phi) v_{i}^{0}}{V_{p i}}$,

408

$\tilde{H}_{p i 23}(s)=\frac{\tilde{\tau}_{p i}}{\tilde{\tau}_{p i} s+1} \cdot \frac{(1-\Phi) T_{p i 1}^{0}+\Phi T_{p c 1}^{0}-T_{p i 2}^{0}}{V_{p i}}, \tilde{H}_{\text {out } 1}(s)=H_{\text {out } 1}(s), \tilde{H}_{\text {out } 2}(s)=H_{\text {out } 2}(s)$

409 in accordance with the notation of Section 3.1, and

410

$$
\tilde{\tau}_{p i}=\frac{1}{\frac{L_{p i} k_{p i}}{\rho_{i} c_{i} V_{p i}}+\frac{v_{i}^{0}}{V_{p i}}} .
$$

\section{4.2. Control design}

412 A stable closed-loop control for the solar heating system (1a-e) is to be realized in such a way 413 that the outlet temperature $T_{\text {out }}(t)$ follows a given reference input $T_{\text {out, }}(t)$ in time accurately 414 enough. It means that $\tilde{T}_{\text {out }}(t)$ is to follow $\tilde{T}_{\text {out }, r}(t)$, where $\tilde{T}_{\text {out }, r}(t)=T_{\text {out }, r}(t)-T_{\text {out }}^{0}$ (see Fig. 10).

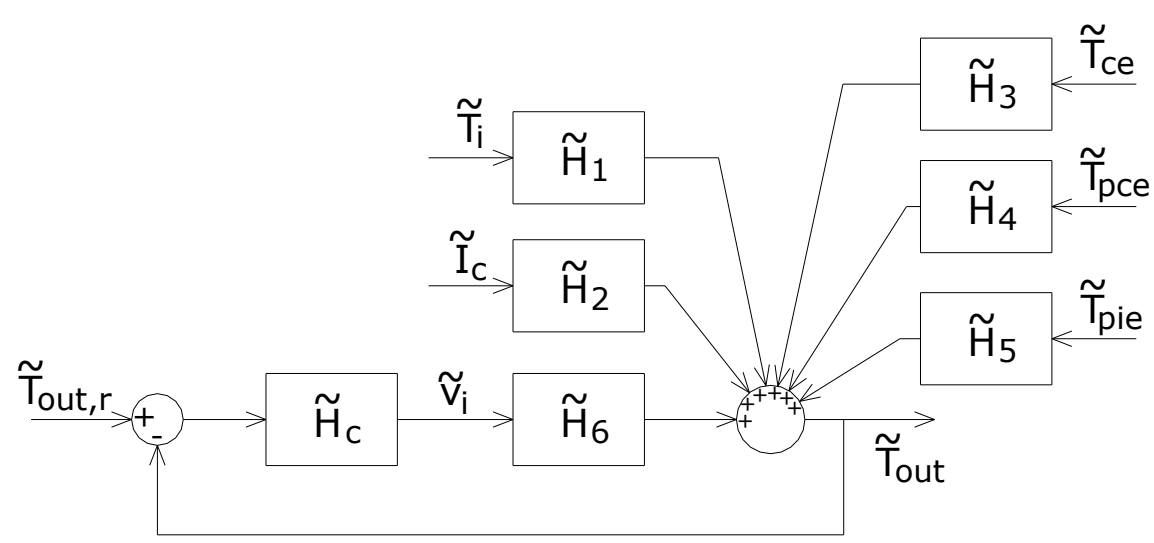

Fig. 10. Feedback control for the solar heating system 
417 The task is to determine $\tilde{H}_{c}$ such that the control is stable with properly small static errors 418 relating to the inputs $\tilde{T}_{o u t, r}, \tilde{T}_{i}, \tilde{I}_{c}, \tilde{T}_{c e}, \tilde{T}_{p c e}, \tilde{T}_{p i e}$. It should be mentioned that the 419 mathematical derivation is not fully detailed below because of limits in volume. For more 420 details, see (Buzás and Kicsiny, 2014; Kicsiny, 2015), where similar derivations can be found 421 (but for different systems). The transfer functions of the (controlled) system of Fig. 10 422 regarding the reference input $\tilde{T}_{\text {out }, r}$ and the disturbances $\tilde{T}_{i}, \tilde{I}_{c}, \tilde{T}_{c e}, \tilde{T}_{p c e}, \tilde{T}_{p i e}$ are given in 423 Eqs. (27)-(32).

$$
\tilde{H}_{\tilde{T}_{\text {out }} \tilde{T}_{\text {out }, r}}(s)=\frac{\tilde{H}_{c}(s) \tilde{H}_{6}(s)}{1+\tilde{H}_{c}(s) \tilde{H}_{6}(s)},
$$

$\tilde{H}_{c}(s) \tilde{H}_{6}(s)$ is the loop gain of the system (multiplying around the feedback control loop). Write $\tilde{H}_{c}(s) \tilde{H}_{6}(s)$ (in (36) and (37)) in the general form $\frac{c_{c}}{s^{i}} \tilde{H}_{0}(s)$ :

$$
\tilde{H}_{c}(s) \tilde{H}_{6}(s)=\frac{c_{c}}{s^{i}} \tilde{H}_{0}(s),
$$

433 where $\tilde{H}_{0}(0)=1$ and $c_{c}$ and $i$ are constant.

434 Consider the cases of $\mathrm{P}$ and PI controls:

$435 \mathrm{P}$

$$
\tilde{H}_{c}(s)=A_{P},
$$

436

PI:

$$
\tilde{H}_{c}(s)=A_{P}\left(1+\frac{1}{s T_{I}}\right)=\frac{A_{P}}{s T_{I}}\left(1+s T_{I}\right),
$$

437 where $A_{P}$ and $T_{I}$ are constant. It can be derived based on Section 4.1 that the product $438 \tilde{H}_{c}(s) \tilde{H}_{6}(s)$ fits into the general form of Eq. (33) in case of both control types, see Eqs. (36) 439 and (37).

440

P:

$$
\tilde{H}_{c}(s) \tilde{H}_{6}(s)=\frac{c_{c, P}}{s^{0}} \tilde{H}_{0}(s)
$$


441 PI:

$$
\tilde{H}_{c}(s) \tilde{H}_{6}(s)=\frac{c_{c, P I}}{s^{1}} \tilde{H}_{0}(s)
$$

442 Take the reference input in the form of Eq. (38) (the disturbances are set zero).

$$
\tilde{T}_{\text {out }, r}(t)=c_{r} t^{j},
$$

444 where $c_{r}$ and $j$ are constant. If $j=0, \tilde{T}_{\text {out, }}(t)$ is a step function, if $j=1, \tilde{T}_{\text {out, }}(t)$ is a ramp 445 function (in our case, only $t \geq 0$ is considered).

446 If it holds that $i>j$ (for $i, j$ in (33) and (38)), then the static error of the control relating to $\tilde{T}_{\text {out, }}$ 447 is zero. If $i>j$ does not hold, the static error relating to $\tilde{T}_{o u t, r}$ is according to Eq. (39) for a P 448 control.

$$
e_{r, s}=\lim _{t \rightarrow \infty}\left(\tilde{T}_{\text {out }, r}(t)-\tilde{T}_{\text {out }}(t)\right)=\frac{c_{r}}{1+c_{c}}
$$

450 If $i>j$ does not hold, the static error relating to $\tilde{T}_{\text {out, }}$ is according to Eq. (40) for a PI control.

$$
e_{r, s}=\lim _{t \rightarrow \infty}\left(\tilde{T}_{\text {out }, r}(t)-\tilde{T}_{\text {out }}(t)\right)=\frac{c_{r}}{c_{c}}
$$

452 Take the disturbance $\tilde{T}_{i}(t)$ in the form of Eq. (41) (the other disturbances and $\tilde{T}_{\text {out, }}(t)$ are set 453 zero).

$$
\tilde{T}_{i}(t)=c_{1} t^{k},
$$

455 where $c_{1}$ and $k$ are constant. If $k=0, \tilde{T}_{i}(t)$ is a step function, if $k=1, \tilde{T}_{i}(t)$ is a ramp function.

456 The transfer function $\tilde{H}_{1}(s)$ relating to $\tilde{T}_{i}$ should be considered in the form of Eq. (42).

$$
\tilde{H}_{1}(s)=\frac{c_{\tilde{T}_{i}}}{s^{l_{1}}} \tilde{H}_{0}^{\widetilde{i}_{i}}(s)
$$

458 where $\tilde{H}_{0}^{\tilde{T}_{i}}(s)=1$ and $c_{\tilde{T}_{i}}$ is constant.

459 If $i>k+l_{1}$ holds for $i, k$ and $l_{1}$ in Eqs. (33), (41) and (42), the static error relating to $\tilde{T}_{i}$ is zero.

460 One can derive based on Section 4.1 that $\tilde{H}_{1}(s)$ really fits into the form of Eq. (42), where $l_{1}$ $461=0$. Furthermore, $\tilde{H}_{2}(s), \tilde{H}_{3}(s), \tilde{H}_{4}(s)$ and $\tilde{H}_{5}(s)$ are also in accordance with Eq. (42), see 462 Eqs. (43)-(46).

$$
\tilde{H}_{2}(s)=\frac{c_{\tilde{l}_{c}}}{s^{l_{2}}} \tilde{H}_{0}^{\tilde{I}_{c}}(s)
$$

464

$$
\tilde{H}_{3}(s)=\frac{c_{\widetilde{T}_{c e}}}{s^{l_{3}}} \tilde{H}_{0}^{\widetilde{T}_{c e}}(s),
$$

$$
\tilde{H}_{4}(s)=\frac{c_{\tilde{T}_{p c e}}}{s^{l_{4}}} \tilde{H}_{0}^{\tilde{T}_{p c e}}(s),
$$




$$
\tilde{H}_{5}(s)=\frac{c_{\widetilde{T}_{p i e}}}{s^{l_{5}}} \tilde{H}_{0}^{\tilde{T}_{p i e}}(s)
$$

467 where $l_{2}=l_{3}=l_{4}=l_{5}=0$. If $i>k+l_{1}$ does not hold, the static error of the control corresponding to $468 \tilde{T}_{i}$ is according to Eq. (47) for a P control.

$$
e_{1, s}=\lim _{t \rightarrow \infty}\left(\tilde{T}_{\text {out }, r}(t)-\tilde{T}_{\text {out }}(t)\right)=\frac{c_{\tilde{T}_{i}}}{1+c_{c}} c_{1}
$$

470 If $i>k+l_{1}$ is not fulfilled, the static error corresponding to $\tilde{T}_{i}$ is according to Eq. (48) for a PI 471 control.

$$
e_{1, s}=\lim _{t \rightarrow \infty}\left(\tilde{T}_{\text {out }, r}(t)-\tilde{T}_{\text {out }}(t)\right)=\frac{c_{\tilde{T}_{i}}}{c_{c}} c_{1}
$$

473 Consider $\tilde{I}_{c}(t), \tilde{T}_{c e}(t), \tilde{T}_{p c e}(t)$ and $\tilde{T}_{p i e}(t)$ similarly as in Eq. (41): $\tilde{I}_{c}(t)=c_{2} t^{m}, \tilde{T}_{c e}(t)=c_{3} t^{n}$, $474 \tilde{T}_{p c e}(t)=c_{4} t^{q}, \tilde{T}_{p i e}(t)=c_{5} t^{u}$, where $m, n, q, u, c_{2}, c_{3}, c_{4}$ and $c_{5}$ are constant.

475 Similarly as above, the static error relating to $\tilde{I}_{c}\left(e_{2, s}\right), \tilde{T}_{c e}\left(e_{3, s}\right), \tilde{T}_{p c e}\left(e_{4, s}\right)$ and $\tilde{T}_{p i e}\left(e_{5, s}\right)$ are 476 zero if $i>m+l_{2}, i>n+l_{3}, i>q+l_{4}$ or $i>u+l_{5}$, respectively. If these conditions are not fulfilled, the 477 static errors are according to Eqs. (49)-(52) for a P control.

$$
e_{2, s}=\frac{c_{\tilde{I}_{c}}}{1+c_{c}} c_{2},
$$

$$
e_{3, s}=\frac{c_{\tilde{T}_{c e}}}{1+c_{c}} c_{3},
$$

$$
e_{4, s}=\frac{c_{\widetilde{T}_{p c e}}}{1+c_{c}} c_{4},
$$

If the above conditions are not fulfilled, the static errors are according to Eqs. (53)-(56) for a 483

$$
e_{5, s}=\frac{c_{\tilde{T}_{p i e}}}{1+c_{c}} c_{5}
$$

$$
e_{2, s}=\frac{c_{\tilde{I}_{c}}}{c_{c}} c_{2},
$$

$$
e_{3, s}=\frac{c_{\tilde{T}_{c e}}}{c_{c}} c_{3},
$$

$$
e_{4, s}=\frac{c_{\tilde{T}_{p c e}}}{c_{c}} c_{4} \text {, }
$$




$$
e_{5, s}=\frac{c_{\tilde{T}_{p i e}}}{c_{c}} c_{5}
$$

The values of the control parameter(s) $A_{P}$ (and $T_{I}$ ) should be selected in such a way that the absolute values of the above static errors are not bigger than a positive prefixed limit $E$ and the control is stable. Considering stability, the controlled system is stable with respect to $\widetilde{T}_{\text {out }, r}$ if the real parts of the zeros of the denominator of $\tilde{H}_{\tilde{T}_{\text {out }}, \tilde{T}_{\text {out }, r}}$ (see Eq. (27)) are negative.

The denominators in (28)-(32) are the same as the denominator in (27) $\left(1+\tilde{H}_{c}(s) \tilde{H}_{6}(s)\right)$, so the same condition with respect to the mentioned zeros is sufficient to assure the stability of the controlled system relating to $\tilde{T}_{i}, \tilde{I}_{c}, \tilde{T}_{c e}, \tilde{T}_{p c e}$ and $\tilde{T}_{p i e}$ as well.

Summing up, the task of determining a $\mathrm{P}$ (or PI) control mathematically is to select the free control parameter(s) $A_{P}$ (and $T_{I}$ ) such that $\left|e_{r, s}\right| \leq E,\left|e_{1, s}\right| \leq E,\left|e_{2, s}\right| \leq E,\left|e_{3, s}\right| \leq E,\left|e_{4, s}\right| \leq E$, $\left|e_{5, s}\right| \leq E$ hold, and the real parts of the zeros of the denominator of $\tilde{H}_{\widetilde{T}_{\text {out }} \tilde{T}_{\text {out }, r}}$ are negative.

\section{Remark 4.1}

The above criterion on the denominator of $\tilde{H}_{\widetilde{T}_{\text {out }} \tilde{T}_{\text {out }, r}}$ is sufficient for the stability of not only the linearized system but the original nonlinear controlled system (in which $v_{i}(t)$ is variable), since, according to Lyapunov, the latter one is stable as well if the real part of each zero of the denominator of $\tilde{H}_{\tilde{T}_{\text {out }}, \tilde{T}_{\text {out }, r}}$ is negative.

\subsubsection{Control design for a real system}

Let us design a proper $\mathrm{P}$ control of the SZIU system specified in Section 3.2. Consider a time period in May. Let $T_{\text {out }}^{0}=55^{\circ} \mathrm{C}$, which is generally high enough for domestic purposes. Let $I_{c}^{0}$ $=600 \mathrm{~W} / \mathrm{m}^{2}$ (approximately the average daytime irradiance on a clear day (in May) in Hungary (Varga, 2011)), $T_{i}^{0}=15{ }^{\circ} \mathrm{C}$ (average tap water temperature), $T_{c e}^{0}=T_{p c e}^{0}=20{ }^{\circ} \mathrm{C}$ (average daytime temperature of the environment), $T_{p i e}^{0}=T_{p i 1}^{0}=15{ }^{\circ} \mathrm{C}$ (underground (soil) temperature). From these assumptions, the remaining values of the equilibrium $T_{c}^{0}, T_{p c 1}^{0}, T_{p c 2}^{0}$, $v_{i}^{0}$ can be calculated from Eqs. (20a-e): $T_{c}^{0}=61.35{ }^{\circ} \mathrm{C}, T_{p c 1}^{0}=59.94{ }^{\circ} \mathrm{C}, T_{p c 2}^{0}=53.88{ }^{\circ} \mathrm{C}, v_{i}^{0}$ $=0.00003 \mathrm{~m}^{3} / \mathrm{s}\left(=1.8 \mathrm{l} / \mathrm{min}\right.$ ). The maximum of $v_{i}$ is $10.5 \mathrm{l} / \mathrm{min}$ (see Section 3.2 ). It is assumed, as a further limitation, that $v_{i}(t)$ can be changed between zero and its maximal value in 3 seconds, from which the (maximal) speed of flow rate changing is $0.000058 \mathrm{~m}^{3} / \mathrm{s}^{2}$.

Let us require that the absolute values of the static errors (39), (47), (49)-(52) are less or equal to $0.2{ }^{\circ} \mathrm{C}$, which is suitable for a DHW producing installation. It is also required that the controlled system is stable that is the real parts of the zeros of the denominator of $\tilde{H}_{\tilde{T}_{\text {out }} \tilde{T}_{\text {out }, r}}$ are negative.

Assume that such high changes of the disturbances act on the system at the same time (at time 10 (min), see Figs. 11, 12, 13 and 14), which are still not impossible but rare even separately under real conditions, thus they are even more unlikely simultaneously. Check in this case if the controlled system can still follow accurately enough a reference input, which is also changed to a great extent in the same time. (If the controlled system is able to follow well an 
extreme reference input under extreme disturbances (with small probabilities), it can be expected that it works even more precisely under more common real circumstances.)

A step input is used as the mentioned reference input (see Fig. 11) and sums of step and trigonometric inputs are used as the mentioned disturbances (see Fig. 12) modelling both sudden and permanent environmental changes.

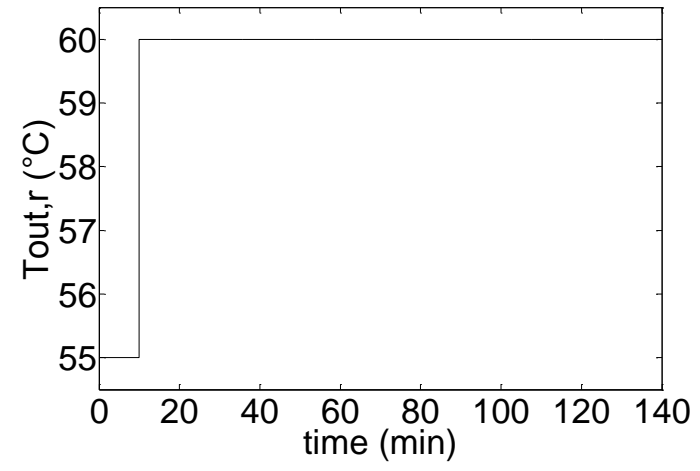

Fig. 11. Reference input for the controlled system
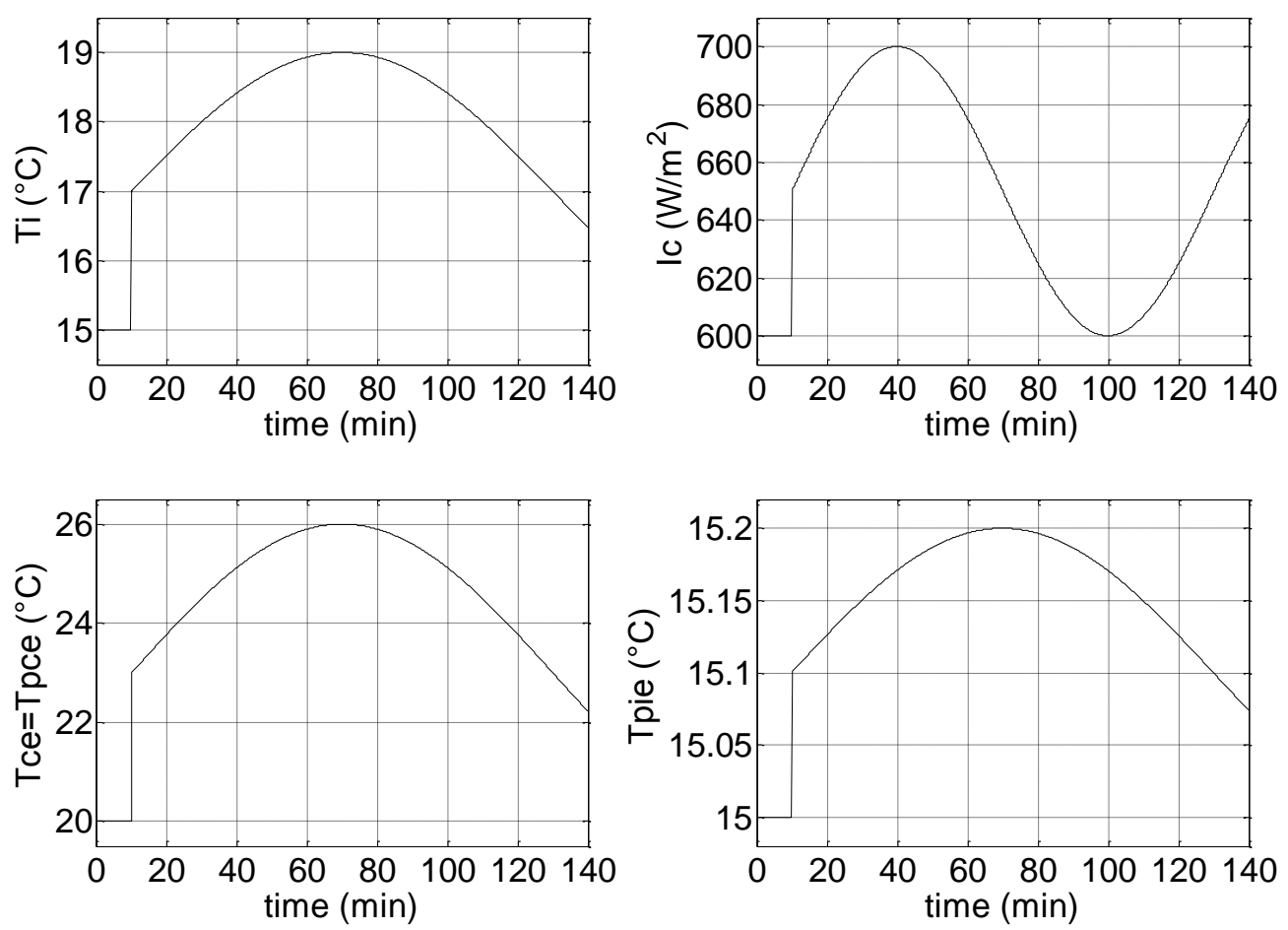

Fig. 12. Disturbances for the controlled system

The control parameter is set $A_{P}=-0.00008$, which assures stability and that the requirements $\left|e_{r, s}\right| \leq 0.2{ }^{\circ} \mathrm{C},\left|e_{1, s}\right| \leq 0.2{ }^{\circ} \mathrm{C},\left|e_{2, s}\right| \leq 0.2{ }^{\circ} \mathrm{C},\left|e_{3, s}\right| \leq 0.2{ }^{\circ} \mathrm{C},\left|e_{4, s}\right| \leq 0.2{ }^{\circ} \mathrm{C},\left|e_{5, s}\right| \leq 0.2{ }^{\circ} \mathrm{C}$ hold.

Apply and test this P control (in (Matlab) Simulink) for the original, not linearized, model (1a-e) for the SZIU system.

The initial state variables are at the equilibrium point (at which the system is suddenly disturbed at the selected initial time $10 \mathrm{~min}): T_{c}(10)=T_{c}^{0}, T_{p c 1}(10)=T_{p c 1}^{0}, T_{p c 2}(10)=T_{p c 2}^{0}$, $T_{p i 1}(10)=T_{p i l}^{0}, T_{i}(10)=T_{i}^{0}, I_{c}(10)=I_{c}^{0}, T_{c e}(10)=T_{c e}^{0}, T_{p c e}(10)=T_{p c e}^{0}, T_{p i e}(10)=T_{p i e}^{0}, \quad v_{i}(10)=v_{i}^{0}$, from which the control has to reduce relatively high initial error: $T_{\text {out }, r}(0)-T_{\text {out }}(0)=5{ }^{\circ} \mathrm{C}$ (see the upper part of Fig. 13). The simulation results are shown in Figs. 13 and 14. Fig. 13 shows 
541 the reference temperature $T_{\text {out, }}(t)$ (input), the outlet temperature $T_{\text {out }}(t)$ (controlled variable) 542 and the pump flow rate $v_{i}(t)$ (manipulated variable).
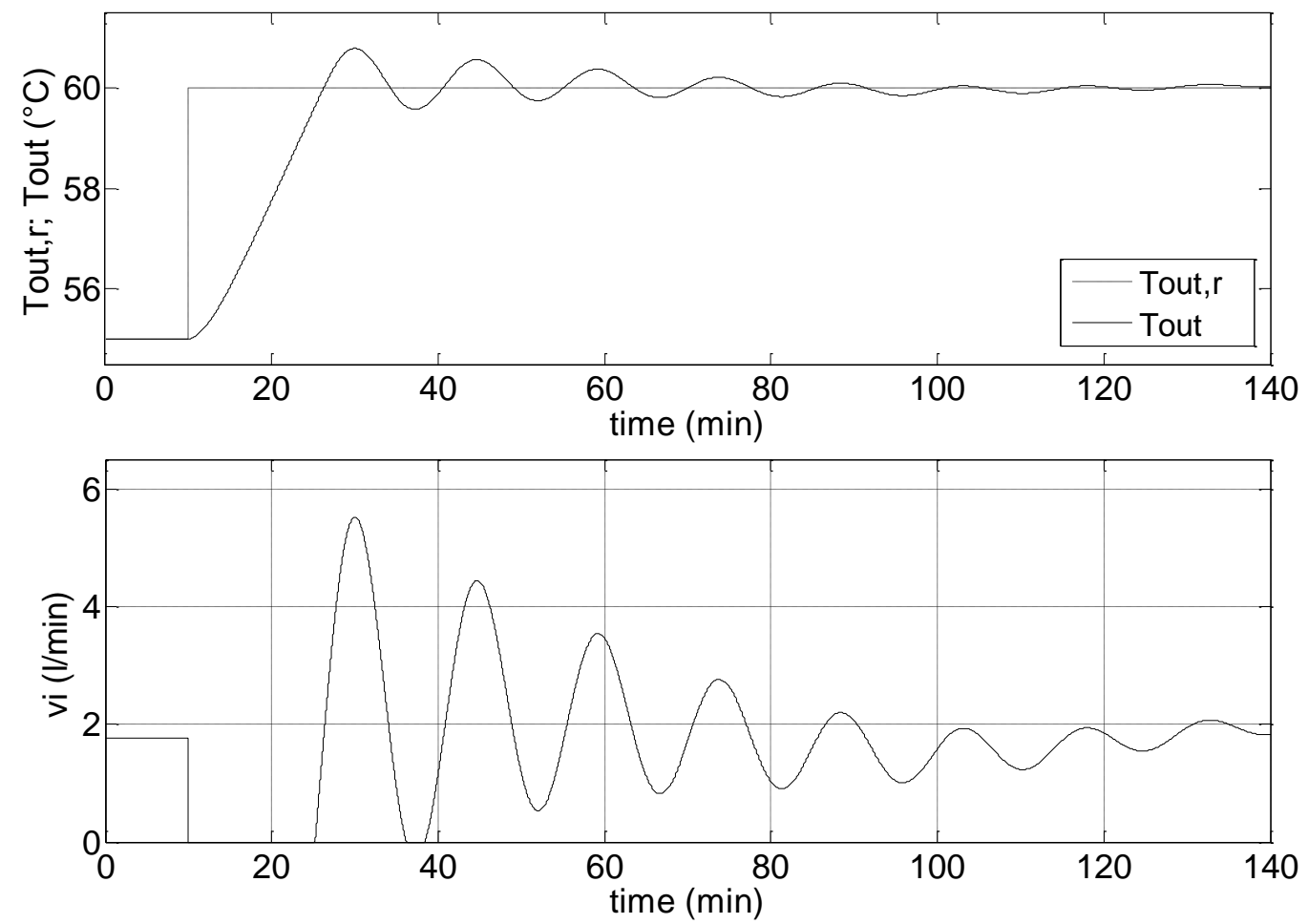

Fig. 13. $T_{\text {out }, r}(t), T_{\text {out }}(t)$ as controlled variable and $v_{i}(t)$ as manipulated variable

545 The error of control $T_{\text {out }, r}(t)-T_{\text {out }}(t)$ is shown in Fig. 14.

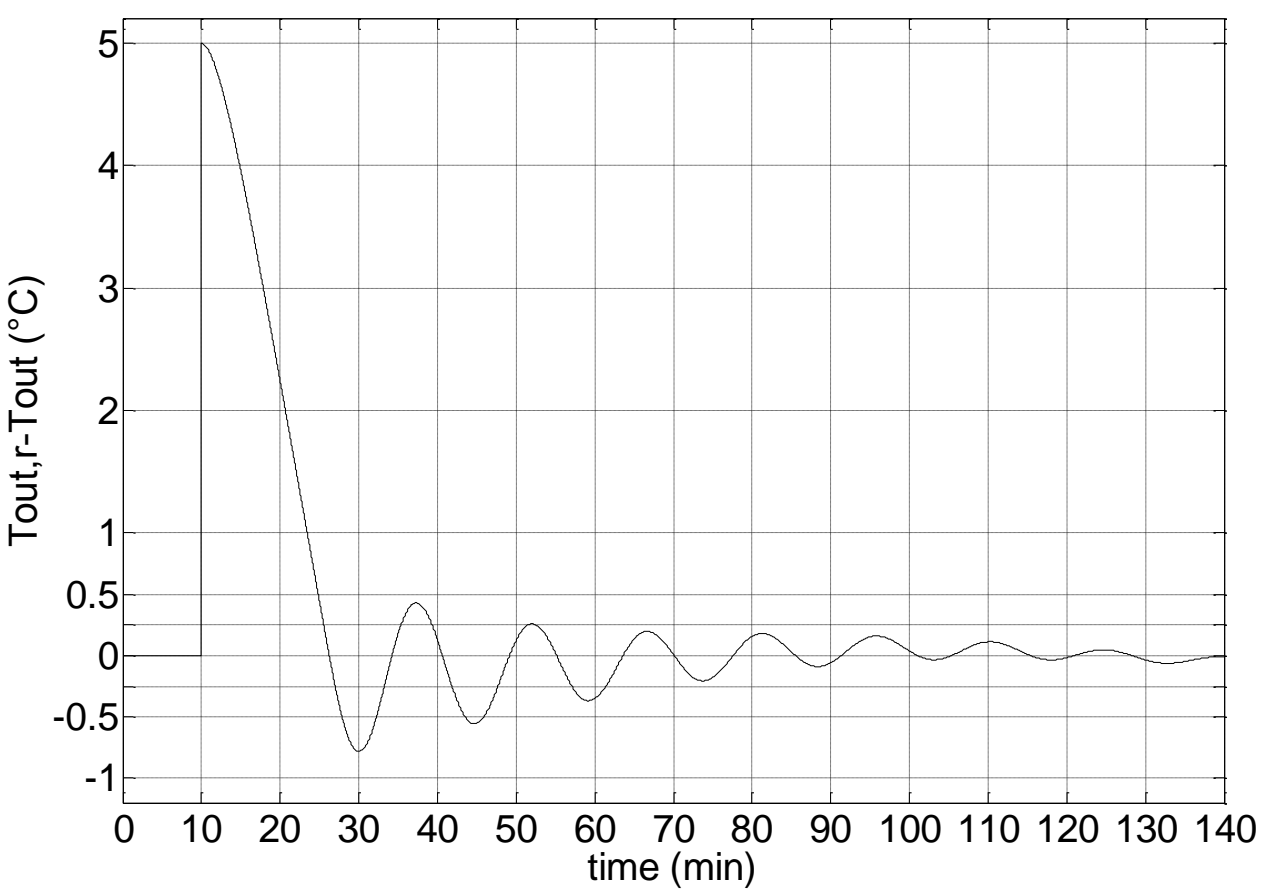

Fig. 14. Error of control $T_{\text {out, }}(t)-T_{\text {out }}(t)$

548 Based on the results on the $\mathrm{P}$ control, the absolute value of the error of control decreases definitively below $1{ }^{\circ} \mathrm{C}$ and $0.5^{\circ} \mathrm{C}$ within $13.5 \mathrm{~min}$ (at $23.5 \mathrm{~min}$, c.f. Fig. 14) and $35.9 \mathrm{~min}$ (at $45.9 \mathrm{~min}$ ), respectively. This speed and precision is convenient for general domestic purposes. 
The absolute value of the error of control decreases definitively below $5 \%$ of the initial error (below $0.25^{\circ} \mathrm{C}$ ) within $51.4 \mathrm{~min}$ (at $61.4 \mathrm{~min}$ ) and definitively below the required limit $0.2{ }^{\circ} \mathrm{C}$ within $54.3 \mathrm{~min}$ (settling time). According to these results, the designed $\mathrm{P}$ control is satisfactorily fast and precise regarding the control purpose.

\section{Remark 4.2}

1. Of course, the DHW produced at the claimed temperature $\left(55^{\circ} \mathrm{C}\right)$ can be stored in a solar storage and can be consumed according to the current hot water demand during the day. If the DHW produced by the worked out control is just at the minimal temperature level required by the consumer, then the produced DHW amount is maximal, so the hot water demand can be satisfied with minimal or without any auxiliary heating costs.

2. The gained results underlie Remark 4.1 regarding the stability of the nonlinear controlled system (in which $v_{i}(t)$ is not constant), since above, the nonlinear system model (1a-e) has been controlled.

\subsubsection{Comparison with on/off control}

For comparison, the most conventional on/off control has been also applied (instead of the P control) for the same system with the same initial conditions above. The control purpose (to follow the reference input of Fig. 11) is also the same. The inlet pump flow rate $v_{i}$ has been modified according to the on/off strategy, that is, it can take a constant (maximal) value or zero. Based on many attempts, $0.2 \mathrm{~m}^{3} / \mathrm{h}=3.3 \mathrm{l} / \mathrm{min}$ (instead of $10.5 \mathrm{l} / \mathrm{min}$ above) has proved to be optimal to minimize the residual amplitude of the oscillating error of control while still be able to follow (on the average) the reference input. Also for the sake of minimizing the residual amplitude of the error, the switch-on and switch-off temperature differences have been set to very low, namely, $0.1^{\circ} \mathrm{C}$ and $-0.1{ }^{\circ} \mathrm{C}$. (Even lower values are not practical because of normal inaccuracies of real temperature sensors.) Figs. 15 and 16 show the results in case of the on/off control, which can be directly compared with those of the P control (see Figs. 13 and 14).
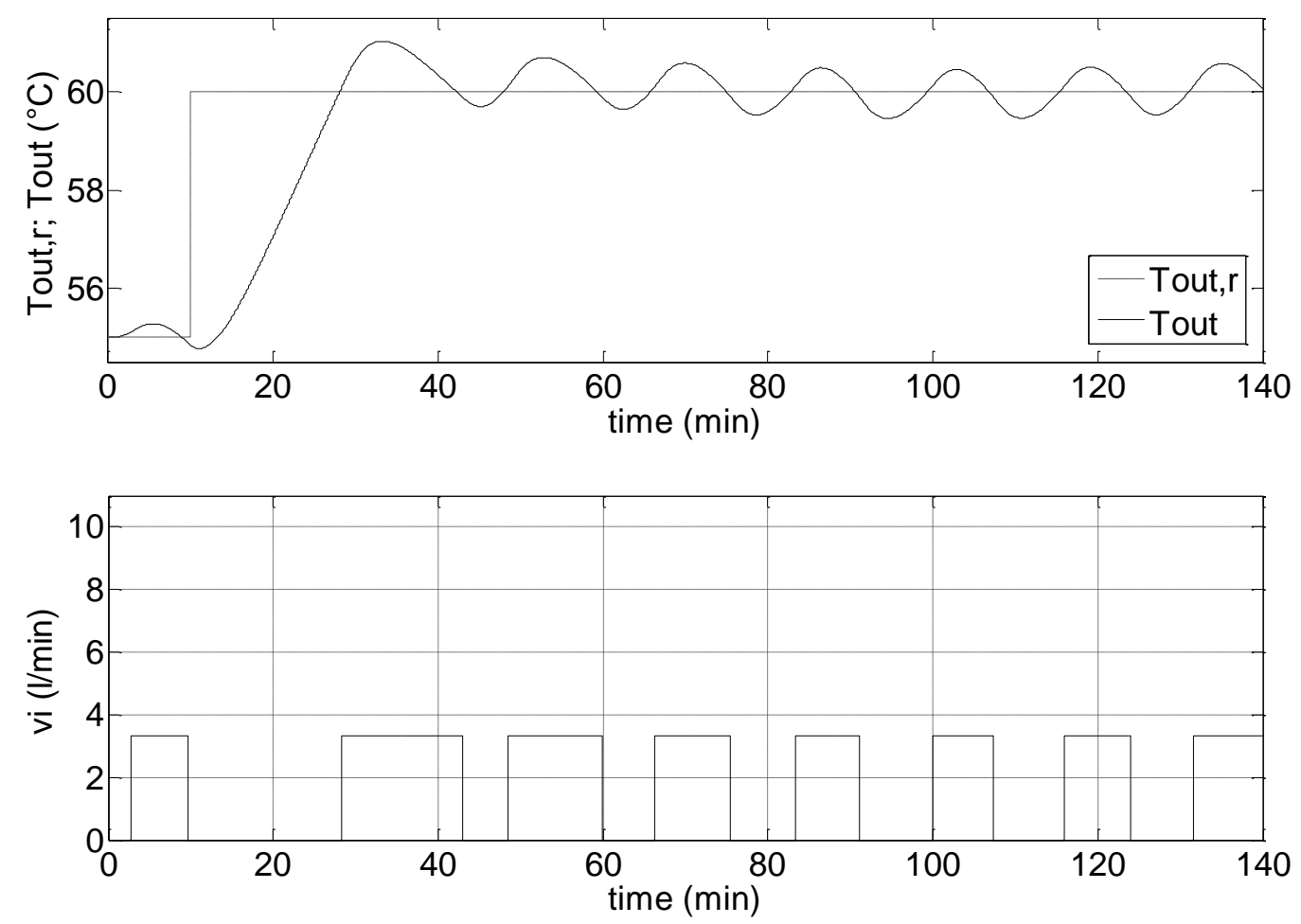
Fig. 15. $T_{\text {out }, r}(t), T_{\text {out }}(t)$ and $v_{i}(t)$ in case of on/off control

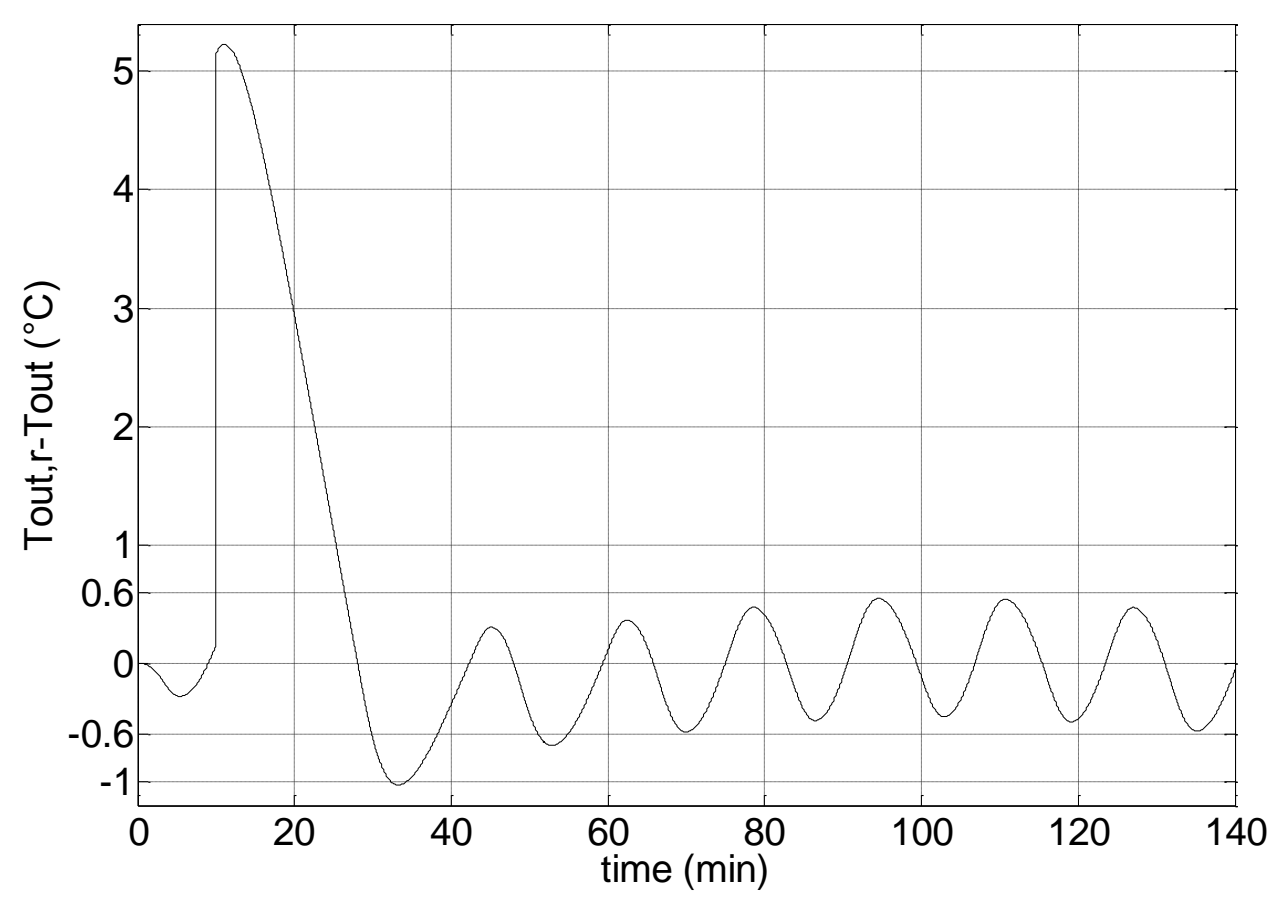

Fig. 16. Error of control $T_{\text {out, }}(t)-T_{\text {out }}(t)$ in case of on/off control

Based on the results on the on/off control, the absolute value of the error of control decreases definitively below $1{ }^{\circ} \mathrm{C}$ and $0.6{ }^{\circ} \mathrm{C}$ within $24.4 \mathrm{~min}$ (at $34.4 \mathrm{~min}$, c.f. Fig. 16) and $44.9 \mathrm{~min}$ (at $54.9 \mathrm{~min}$, respectively. This speed and precision can be still satisfactory for not strict domestic purposes, nevertheless, it can be seen that the $\mathrm{P}$ control is considerably faster and more precise than the on/off control. Even the on/off control cannot meet the requirements of that the absolute error decreases definitively below $0.5{ }^{\circ} \mathrm{C}$ or $5 \%$ of the initial error $\left(0.25{ }^{\circ} \mathrm{C}\right)$ or $0.2^{\circ} \mathrm{C}$, which are not problem for the $\mathrm{P}$ control.

\section{Conclusion}

It can be stated generally that modelling based on transfer functions is a relatively new and not frequent approach in analysing solar heating systems, more particularly, in case of domestic purposes. Accordingly, control design based on transfer functions is quite rare in case of such systems in spite of the simple applicability, which is an important advantage of the linear method in connection with transfer functions. Transfer function based controls are usually simpler than optimal or (nonlinear) model based controls but able to follow the reference signal more precisely than the most conventional on/off control. Although, pipes can affect the operation of solar heating systems considerably, this effect has not been built in the transfer functions of such systems worked out already in the literature. It has been intended to contribute to fulfil the above research gaps in this paper by working out new transfer functions considering pipes and designing stable controls (a closed-loop P control as a particular application) based on the proposed transfer functions.

In addition, the transfer functions have been used for the dynamic analysis of a particular solar heating system (the SZIU system). The worked out stable P control has been also applied for the SZIU system to make the outlet temperature of the system follow a given reference input. If this reference input is just the minimal temperature level required by the consumer, then the produced DHW amount is maximal, so the hot water demand can be satisfied with minimal or without any auxiliary heating cost. 
In accordance with a future research task set in the Conclusion of (Kicsiny, 2015), the present 608 study gives an extension of the research results of (Buzás and Kicsiny, 2014 and Kicsiny, 609 2015), where transfer functions, dynamic analysis and a corresponding control have been worked out for solar collectors and solar heating systems without considering pipe effects. It can be stated based on the applications of this paper that the worked out transfer functions can be successfully and easily applied for dynamic analysis and control design with the mathematical methods of control engineering. In particular, the designed $\mathrm{P}$ control is appropriate with respect to the control purpose because of its rapidity and precision even in case of highly changed disturbances and reference input. In comparison with the most common on/off control, the $\mathrm{P}$ control has proved to be considerably faster and more precise. Essentially, the presented dynamic analysis can be adapted easily for any solar heating system equipped with an external heat exchanger. The derived control design can be used for many solar heating systems if the outlet temperature has to follow a reference signal in time (e.g. solar desalination plants and solar power plants). Pumps with variable flow rate needed for the worked out control are already widely used in the practical field of solar heating systems.

Further researches may deal with the determination of so-called describing functions, which correspond to nonlinear mathematical models for solar heating systems and can be gained from harmonic linearization (a linearization method other than the one used in this paper, which can be applied for dynamic analysis and for control design as well).

\section{Acknowledgement}

The author thanks the Editor for the encouraging help in the submission process and the anonymous Referees for their valuable comments to improve this work. The author also thanks the staff of the Department of Mathematics (Faculty of Mechanical Engineering, SZIU) for their contribution, Dr. János Buzás for the photos on the measured system and the Department of Physics and Process Control for the measured data.

This paper was supported by the János Bolyai Research Scholarship of the Hungarian Academy of Sciences.

\section{References}

Araújo, A., Pereira, V., 2017. Solar thermal modeling for rapid estimation of auxiliary energy requirements in domestic hot water production: On-off flow rate control. Energy 119, 637651.

Ayala, C.O., Roca, L., Guzman, J.L., Normey-Rico, J.E., Berenguel, M., Yebra, L., 2011. Local model predictive controller in a solar desalination plant collector field. Renew. Energy 36, 3001-3012.

Badescu, V., 2008. Optimal control of flow in solar collector systems with fully mixed water storage tanks. Energy Convers. Manag. 49, 169-184.

Bakshi, U.A., Bakshi, V.U., 2007. Linear Control Systems, Technical Publications Pune, India.

Bettayeb, M., Nabag, M., Al-Radhawi, M.A., 2011. Reduced order models for flat-plate solar collectors, GCC Conference and Exhibition (GCC), 2011 IEEE, 369-372.

Bíró-Szigeti, Sz., 2014. Strategy support of residential energy saving investments in Hungary with the method of technology roadmapping. Acta Polytech. Hung. 11 (2), 167-186.

Buzás, J., Farkas, I., Biró, A., Németh, R., 1998. Modelling and simulation of a solar thermal system. Math. Comput. Simul. 48, 33-46.

Buzás, J., Farkas, I., 2000. Solar domestic hot water system simulation using block-oriented software, The $3^{\text {rd }}$ ISES-Europe Solar World Congress (Eurosun 2000), Copenhagen, Denmark, CD-ROM Proceedings (2000), pp. 9.

Buzás, J., Kicsiny, R., 2014. Transfer functions of solar collectors for dynamical analysis and control design. Renew. Energy 68, 146-155. 
Camacho, E.F., Rubio, F.R., Berenguel, M., Valenzuela, L., 2007a. A survey on control schemes for distributed solar collector fields. Part II: Advanced control approaches. Solar Energy 81, 1252-1272.

Camacho, E.F., Rubio, F.R., Berenguel, M., Valenzuela, L., 2007b. A survey on control schemes for distributed solar collector fields. Part I: Modeling and basic control approaches. Solar Energy 81, 1240-1251.

Duffie, J.A., Beckman, W.A., 2006. Solar Engineering of Thermal Processes, John Wiley and Sons, New York.

Etter, D.M., Kuncicky, D., Moore, H., 2004. Introduction to MATLAB 7, Springer.

Farkas, I., Buzás, J., Lágymányosi, A., Kalmár, I., Kaboldy, E., Nagy, L., 2000. A combined solar hot water system for the use of swimming pool and kindergarten operation, Energy and the environment, Vol. I. /ed. by B. Frankovic/, Croatian Solar Energy Association, Opatija, 81-88.

Fontalvo, A., Garcia, J., Sanjuan, M., Padilla, R.V., 2014. Automatic control strategies for hybrid solar-fossil fuel plants. Renew. Energy 62, 424-431.

Huang, B.J., Wang, S.B., 1994. Identification of solar collector dynamics using physical model-based approach. J. Dyn. Syst. Measurement Control 116, 755-763.

Kalogirou, S.A., 2000. Applications of artificial neural-networks for energy systems. Appl. Energy 67, 17-35.

Kicsiny, R., Nagy, J., Szalóki, Cs., 2014. Extended ordinary differential equation models for solar heating systems with pipes. Appl. Energy 129, 166-176.

Kicsiny, R., 2015. Transfer functions of solar heating systems for dynamic analysis and control design. Renew. Energy 77, 64-78.

Kicsiny, R., 2017. Grey-box model for pipe temperature based on linear regression. Int. J. Heat Mass Transfer 107, 13-20.

Kovarik, M., Lesse, P.F., 1976. Optimal control of flow in low temperature solar heat collectors. Sol. Energy 18, 431-435.

Löf, G., 1993. Active Solar Systems, MIT Press.

Maplesoft, 2003. Maple 9 Learning Guide, Waterloo Maple Inc.

Ntsaluba, S., Zhu, B., Xia, X., 2016. Optimal flow control of a forced circulation solar water heating system with energy storage units and connecting pipes. Renew. Energy 89, 108124.

Orbach, A., Rorres, C., Fischl, R., 1981. Optimal control of a solar collector loop using a distributed-lumped model. Automatica 17 (3), 535-539.

Pontryagin, L.S., Boltyanskii, V.G., Gamkrelidze, R.V., Mishchenko, E.F., 1962. The Mathematical Theory of Optimal Processes, Wiley, New York.

Varga, P., 2011. Renewable energies, http://energetika.13s.hu/pub/_epuletenergetika_szakirany_/megujulo\%20energiaforrasok/ Naplopo/EPGEP_Napkollektorok-1\%5B1\%5D.ppt (in Hungarian) [25. 07. 2016]

Winn, C.B., Hull, D.E., 1979. Optimal controllers of the second kind. Sol. Energy 23, 529534. 